NOTICE: this is the author's version of a work that was accepted for publication in Materials and Design. Changes resulting from the publishing process, such as peer review, editing, corrections, structural formatting, and other quality control mechanisms may not be reflected in this document. Changes may have been made to this work since it was submitted for publication. A definitive version was subsequently published in Materials and Design, Vol. 60 (2014). DOI: 10.1016/j.matdes.2014.04.038. 


\section{Elsevier Editorial System(tm) for Materials and Design Manuscript Draft}

Manuscript Number: JMAD-D-13-04293R3

Title: Experimental and numerical study of composite lightweight structural insulated panel with Expanded Polystyrene core against windborne debris impacts

Article Type: Original Article

Keywords: Composite; lightweight; structural insulated panel; windborne debris impact; penetration resistant capacity; laboratory test

Corresponding Author: Dr. Wensu Chen, Ph.D.

Corresponding Author's Institution: Curtin University

First Author: Wensu Chen, Ph.D.

Order of Authors: Wensu Chen, Ph.D.; Hong Hao, PhD, Professor

Abstract: Natural disasters such as cyclone, hurricane, tornado and typhoon cause tremendous loss around the world. The windborne debris usually imposes high speed localized impact on the building envelope, which may harm people inside the building and create dominant openings. A dominant opening in the building envelope might cause internal pressure increasing and result in substantial damage to the building structures, such as roof lifting up or even collapse. To withstand the impact of such extreme event, the penetration resistant capacity of wall or roof panels to windborne debris impact should meet the requirements specified in the wind loading codes, e.g., the Australian Wind Loading Code (AS/NZS 1170.2:2011) [1]. In this study, a composite SIP (i.e. Structural Insulated Panel) with EPS (i.e. Extended Polystyrene) core sandwiched by flat metal skins that is commonly used in building industry was investigated. To study the structural response and penetration resistant capacity of the composite panel against windborne debris impacts, a series of laboratory tests were carried out by using a pneumatic cannon testing system. The effects of various specimen configurations, impact locations and debris impact velocities on their performance were investigated. The failure modes under various projectile impact scenarios were observed and compared by using two high-speed cameras. The dynamic responses were examined quantitatively in terms of the opening size, residual velocity of projectile, deformation and strain time histories on the back skin measured in the tests. The penetration resistance capacity of the panels subjected to windborne debris impact were examined and analyzed. In addition, numerical models were developed in LS-DYNA to simulate the response and damage of the composite SIP under windborne debris impact. Laboratory tested panels were first modeled. The test data was used to calibrate the accuracy of the numerical model. The validated numerical model was then used to conduct more numerical simulations to obtain more results such as energy absorption, impact force and vulnerability curve of the SIP against windborne debris impact. 
- A composite SIP panel with EPS against windborne debris impact was studied

- Laboratory tests were carried out by using a pneumatic cannon testing system

- The failure modes and response of specimens were observed and discussed

- Penetration-resistant capacity of SIP against debris impacts was identified

- Numerical model was developed to simulate the test by using LS-DYNA 


\title{
Experimental and Numerical Study of Composite Lightweight Structural Insulated Panel with Expanded Polystyrene Core against Windborne Debris Impacts
}

\author{
Wensu Chen* and Hong Hao \\ Tianjin University and Curtin University Joint Research Center on Structural Monitoring and Protection, \\ School of Civil and Mechanical Engineering, \\ Curtin University \\ Kent Street, Bentley, WA 6102, Australia
}

\begin{abstract}
Natural disasters such as cyclone, hurricane, tornado and typhoon cause tremendous loss around the world. The windborne debris usually imposes high speed localized impact on the building envelope, which may harm people inside the building and create dominant openings. A dominant opening in the building envelope might cause internal pressure increasing and result in substantial damage to the building structures, such as roof lifting up or even collapse. To withstand the impact of such extreme event, the penetration resistant capacity of wall or roof panels to windborne debris impact should meet the requirements specified in the wind loading codes, e.g., the Australian Wind Loading Code (AS/NZS 1170.2:2011). In this study, a composite Structural Insulated Panel (SIP) with Extended Polystyrene (EPS) core sandwiched by flat metal skins that is commonly used in building industry was investigated. To study the structural response and penetration resistant capacity of the composite panel against windborne debris impacts, a series of laboratory tests were carried out by using a pneumatic cannon testing system. The effects of various specimen configurations, impact locations and debris impact velocities on their performance were investigated. The failure modes under various projectile impact scenarios were observed and compared by using two high-speed cameras. The dynamic responses were examined quantitatively in terms of the opening size, residual velocity of projectile, deformation and strain time histories on the back skin measured in the tests. The penetration
\end{abstract}

\footnotetext{
*Corresponding author. E-mail address: wensu.chen@curtin.edu.au Tel: +61426261258
} 
resistance capacity of the panels subjected to windborne debris impact were examined and analyzed. In addition, numerical models were developed in LS-DYNA to simulate the response and damage of the composite SIP under windborne debris impact. Laboratory tested panels were first modeled. The test data was used to calibrate the accuracy of the numerical model. The validated numerical model was then used to conduct more numerical simulations to obtain more results such as energy absorption, impact force and vulnerability curve of the SIP against windborne debris impact.

Keywords: Composite; lightweight; structural insulated panel; windborne debris impact; penetration resistant capacity; laboratory test

\section{Introduction}

Hurricane Andrew in 1992 was recorded by that time as the most destructive and expensive natural disaster in US history, which caused $\$ 25$ billion damage and 65 deaths [2]. The post storm investigation found the hurricane created enormous amount of windborne debris and the windborne debris impact is highlighted as a major cause of damage to building envelope including wall, roof, door, windows shutters or screens etc.[3]. Windward wall is the most prone to debris impact among the building envelope. In a windstorm, unfixed objects or fixed objects such as roof tiles, roof gravel and rafter, etc which might turn loose under strong wind are the primary sources of potential windborne debris. The windborne debris can be classified into three types i.e. compact-like, rod-like and sheet-like [4]. Medium sized timber of 5.4 6.8kg, $100 \mathrm{~mm} \times 50 \mathrm{~mm}$ was found as the most representative of the windborne debris [5]. If wind speed is fast enough, the windborne debris might penetrate the building envelope, imposing threats to people inside the building. It also creates an opening. The opening in the envelope allows excessive amount of wind and rain to enter the building. Moreover, the opening might cause internal pressures increasing which results in more severe damage to the building such as collapse of the structural panel, entire roof lift-off, and total structure failure as 
illustrated in Figure 1. Therefore, the windborne debris is a decisive factor to the performance of the building envelope and the building envelope is crucial to the performance of buildings in windstorms $[3,6]$.

To protect the structure, the US and Australia have developed national and regional guidelines and design standards to address the issue of windborne debris impact on the building envelope and its components. Since 1970's, extensive research work has been undertaken at the Wind Science and Engineering Research Center (WISE) of Texas Tech University (TTU), Florida A\&M, University of Florida (UF) and Florida State University etc in the US [8]. The research about the acceptance criteria of debris resistance of the building envelope has been adopted by the guidelines and codes [9-13]. Resisting the impact without perforation of a $4 \mathrm{~kg}$ lumber with a cross-section of $100 \mathrm{~mm} \times 50 \mathrm{~mm}$ launched at a speed of $15 \mathrm{~m} / \mathrm{s}$ is the most commonly used criterion in these codes. In Australia, the Design Guideline for Queensland Public Cyclone Shelters [14] provides a mandatory requirement for the windborne debris impact resistance for occupant protection. For all the ordinary buildings in cyclonic areas in Australia, Australian Wind Loading Code (AS/NZS 1170.2:2011) [1] specifies that the impact loading from windborne debris should be equivalent to (a) timber projectile of $4 \mathrm{~kg}$ mass with a nominal cross-section of $100 \mathrm{~mm} \times 50 \mathrm{~mm}$ impacting end and impacting velocity of $0.4 \mathrm{~V}_{\mathrm{R}}$ for horizontal trajectories and $0.1 \mathrm{~V}_{\mathrm{R}}$ for vertical trajectories; and (b) Spherical steel ball $8 \mathrm{~mm}$ diameter (approximately 2 grams mass) impacting at $0.4 \mathrm{~V}_{\mathrm{R}}$ for horizontal trajectories and $0.3 \mathrm{~V}_{\mathrm{R}}$ for vertical trajectories where $V_{R}$ is the regional wind speed [1]. It should be noted that the Australian Wind Loading code of 2011 version increases the requirement of structural panel capacity to resist windborne debris impact. In particular, the debris impact velocity is increased from $15 \mathrm{~m} / \mathrm{s}$ in the 2002 edition of the Australian Wind Loading Code to a velocity of $0.4 \mathrm{~V}_{\mathrm{R}}$, which could be $40 \mathrm{~m} / \mathrm{s}$ in regions with the extreme wind velocity reaching $100 \mathrm{~m} / \mathrm{s}$. This substantial increment imposes great challenges for designing new penetration resistant panels to meet the acceptance criterion. It also raises the question regarding the safety of existing panels commonly used in construction industry designed 
according to the previous criterion.

Structural insulated panel (SIP) is a lightweight composite structure which is used in a wide range of commercial, industrial and residential building industry. It consists of insulating polymer foam sandwiched by two layers of structural skins. Two layers of skins can be metal sheet, fibre cement sheet, plywood sheet and oriented strand board etc. The foam can be either Extended Polystyrene (EPS), extruded polystyrene foam (XPS) or polyurethane foam (PU), etc. The SIP panels are considered as sustainable, economical, easy to install, ultra-lightweight, thermal insulated, moisture resistant, acoustic insulated, and flame retardant panels. The performances of some SIP have been investigated. Mousa and Uddin [15] studied a composite structural insulated panels (CSIP) made of thermoplastic orthotropic glass-PP (i.e. glass/polypropylene) laminate as skins and EPS as core. Its global buckling behavior was investigated when it was subjected to concentric and eccentric in-plane loadings. Smakosz and Tejchman [16] studied the strength, deformability and failure mode of the CSIP which consists of glass-fiber reinforced magnesia cement boards as skins and EPS as a core. It was found CSIP has potential as load-bearing elements in buildings such as roofs, floors and walls with respect to their high strength. However, no investigation into the SIP subjected to windborne debris impact has been found in the literatures.

Various testing facilities including drop weight, pendulum, catapult, Hopkinson pressure bar and gas gun have been utilized for impact testing [17-21]. In accordance with the above mentioned testing guideline [10] and FEMA P-320/361 [9, 13] , large projectile cannon facilities have been developed at TTU and UF to simulate windborne debris impacts. A large amounts of structural components or assemblies of buildings including metal panel, CMU (i.e. concrete masonry unit), concrete wall, stud wall, hollow core slab, weatherboard, cladding, glazing and shutter etc have been tested by using pneumatic cannon facility $[22,23]$. However, no study of SIP subjected to projectile impact has been found in the literatures. 
In the above mentioned testing, the acceptance criterion that a test can be considered a pass is the projectile being rejected by the specimen without perforation. Perforation implies the projectile passed through the specimen while penetration means the projectile made an indention or embedded itself into the specimen but not through [13]. A review on penetration and perforation of plates and cylinders by free-flying projectiles has been conducted by Corbett et al. [24]. Backman and Goldsmith [25] reported a comprehensive survey of the mechanics of penetration of projectiles into targets and identified eight possible occurring failure modes for thin or intermediate targets including fracture, spalling, scabbing, plugging, petaling in the back and front plates, and fragmentation. The failure modes vary for different targets with different target thickness and material, projectile geometry and velocity. The behavior of steel plates impacted by blunt-nose cylindrical projectiles has been studied and all steel plates failed by shear plugging [26]. Polyurea coasted composite aluminum plates subjected to high velocity projectile impact was studied. The polyurea coating was found effective in reduction of the residual velocity of projectile and energy absorbing [27]. The damage of sandwich panels are characterized as front skin failure, core failure and back skin failure [28, 29]. Shear failure occurs when the relatively thick skins do not experience large deformation and the membrane forces are not well developed. Tensile failure takes place when the relatively thin skins experience large deformation and the tensile forces are developed. The back skin usually deforms in shear-bending form and the core experiences shear failure [30]. Finite element analysis of penetration of aluminum plates impacted by titanium impactor was conducted by using LS-DYNA to simulate the uncontained engine debris impact on fuselage-like skin panels [31]. The EPS foam subjected to multiple loading and unloading has been modeled by using low density material model in LS-DYNA and calibrated using test results [32].

In this study, composite SIP with EPS core sandwiched by flat metal skins currently commonly used as building envelopes were analyzed. To investigate the structural response and impact resistance of the SIPs subjected to the timber projectile and steel ball impacts as specified in Australian Wind Loading Code (AS/NZS 1170.2:2011) [1], a series of laboratory tests were carried out by using 
pneumatic cannon testing system. The influences of specimen configurations, impact locations and debris impact velocities on their performance have been investigated. The failure modes under various impact scenarios were observed and compared. The dynamic responses were examined quantitatively in terms of the opening size, residual velocity of projectile, deformation and the strain time histories of the back skin of the specimens. The test results indicate that steel ball impact is not critical to the SIP panels. It induced significantly smaller panel responses as compared to that by the $4 \mathrm{~kg}$ timber projectile because of its smaller impact energy owing to its small mass. Steel ball did not perforate the tested panels even at impact velocity higher than $40 \mathrm{~m} / \mathrm{s}$. For these reasons, hereafter only the responses of SIP panels to timber projectile impacts are discussed. The test results of penetration resistance capacity of SIP subjected to wooden projectile impacts are assessed and analyzed in detail in this paper. In addition, a numerical model is developed in LS-DYNA to simulate the SIP responses to wooden projectile impacts. The experimental tests are used to calibrate the numerical model. The predicted data from the numerical simulations are compared with the experimental results. The validated numerical model is then used to calculate the energy absorption, impact force and used to generate the vulnerability curve of the SIP panel subjected to projectile impacts of various masses and velocities.

\section{Experimental investigations}

A total of eight specimens were designed and manufactured for this study. The experiments were carried out by using pneumatic canon test system to investigate the structural response of the specimens subjected to timber projectile impact. The structural response quantities including the opening size, the residual velocity of projectile after perforation, the deformation and the strain time histories of the back skin of the specimens were measured in the tests. The deformation modes of specimens are observed and discussed in this paper. The specimens, the pneumatic impact testing system and the experimental procedures are detailed in the following.

\subsection{Description of the specimens}


The SIP (named as "FSS") consists of an EPS core and two thin flat metal skins. The dimension of specimens is $1200 \mathrm{~mm}$ by $762 \mathrm{~mm}$ which is the standard size of single panel in the building industry. The skins are made of $0.40 \mathrm{~mm}$ Zincalume AZ150 with grade G300 steel. EPS is a lightweight recyclable closed-cell cellular plastic material which is widely used in a variety of protective applications, such as product packaging, helmet liner, thermal insulation and energy absorber, etc. It has good compression strength per weight ratio. However, it should not be exposed to open flame even though flame retardant addictive has been added [33]. In this study, EPS with class SL and density of $13.5 \mathrm{~kg} / \mathrm{m}^{3}$ has been utilized. The EPS cores with three thicknesses (i.e. $37.2 \mathrm{~mm}, 49.4 \mathrm{~mm}$ and $74.2 \mathrm{~mm}$ ) were prepared. Suprasec $₫ 7113$ adhesive was used to glue the core and the skins as commonly used in practice in fabricating the SIP panels. It is a sprayable and flexible polyurethane adhesive, which is suitable for bonding a wide range of materials including polystyrene foam, timber, plastic and metallic. The strength is about 6 7 MPa [34].

Parameters including specimen dimensions and configurations, boundary conditions, impact location, impact projectile mass and velocities affect the performance of SIP panel against projectile impact. The current tests focused on the effect of specimen size, core thickness, impact location and projectile velocity on the specimen performance. The specimen specification and testing scheme are given in Table 1. The panel performances are examined based on the penetration resistance, opening size, residual velocity of projectile, strain and deflection of the back skin.

\subsection{Experimental setup}

The experimental apparatus used in this study consists of a pneumatic cannon, a chronograph, a timber projectile, support frame, LVDTs, strain gauges, data acquisition system, grid chart, two high speed cameras, and halogen lights as shown in Figure 2. The specimens are located $3 \mathrm{~m}$ in front of the pneumatic cannon. The specimens are mounted on the support frame by using G-Clamps on four edges, as shown in Figure $3(\mathrm{~L})$.

\section{- Pneumatic cannon and chronograph}


A pneumatically actuated cannon launch the projectile at a desired velocity, which is used to simulate the windborne debris driven by the wind. The pneumatic cannon can be adjusted to the specified impact location in lieu of its horizontal and vertical mobility as shown in Figure 3 (R). The projectile velocity varies by adjusting the air pressure inside the air chamber. The pressure-velocity relationship is obtained through large amounts of repeated testing for different types of projectiles. In this study, $4 \mathrm{~kg}$ timber projectile with an impacting cross-section of dimension $100 \mathrm{~mm}$ by $50 \mathrm{~mm}$ was launched from the pneumatic cannon. The pressure-velocity relationship has the accuracy of $\pm 1 \mathrm{~m} / \mathrm{s}$ tolerance, which ensures launching the projectile at a desired velocity by pressuring the air pump. The projectile velocity of up to $44 \mathrm{~m} / \mathrm{s}$ can be achieved, which satisfies the testing requirement of Australian Wind Loading Code (AS/NZS 1170.2:2011) [1]. In the tests, a chronograph called Digital Chronograph Cei-3800 was installed at the exit of the barrel to record the actual projectile velocity. The actual impacting velocity can also be checked by high-speed camera images.

\section{- Measurement (LVDT \& strain gauge)}

As shown in Figure 4 (L), two laser Linear Voltage Displacement Transducers (LVDT Keyence LB-70) were used to measure the displacement time history at the back skin (i.e. L2 and L3). To measure the residual velocity of the projectile after penetration or rebound, grid chart was used with the high speed camera. Four strain gauges (S0-S3) with gauge resistance of $119.8 \pm 0.2 \Omega$ and gauge factor of $2.1 \pm 1.0 \%$ were also adhered to the back skin of specimen to measure the strain history, as shown in Figure 4 (R). Strain gauges S1 and S2 were used to measure strains in two directions at the centre of the back skin. Strain gauges S0 and S3 were used to measure strains at the locations a quarter of panel length away from the edge.

\section{- Data Acquisition Unit and high speed camera}

High frequency data acquisition unit consists of DAQ9174 (4 slots), NI-9237 (for strain gauge) and NI-9215 (for LVDT recording displacement) made by National Instruments [35], which is shown in Figure $5(\mathrm{~L})$. The sampling rate of $25 \mathrm{kHz}$ has been used in this study. The data-logging software NI LabVIEW SignalExpress was used to record data from the data acquisition unit. Two high speed 
cameras of up to 40,000 fps (frames per second) shown in Figure 5 (R) are used to record the damage process of the specimens from the front and back views. Both cameras were set as $1000 \mathrm{fps}$ at its resolution of $640 \times 512$ pixels. Four halogen lights of $1500 \mathrm{w}$ were placed to provide intensive light to meet the requirement for capturing high speed images. The high speed camera was connected to a laptop on which commercial software MotionblitzCube was installed for managing the recording process.

\subsection{Experimental results}

Windborne debris impact testing specified in Australian Wind Loading Code (AS/NZS 1170.2:2011) is qualitative as the assessment only provides a pass/fail outcome and no quantitative measurements. In this study, both qualitative and quantitative results were obtained to better understand the structural response of specimens subjected to the debris impact loading. Detail observations on the deformation/failure modes of the specimens are firstly presented in the following.

Based on the observations, the deformation/failure modes of specimens are classified into "Pass"or "Fail" according to the code specification, i.e., if no perforation that generates an opening in the specimen, it is classified as "Pass" irrespective of the deformation level. Based on this, the specimens FSS1, FSS3, FSS7 and FSS8 experienced tearing at the front skin and core but no penetration occurred at the back skin are classified as "Pass". All others specimens that experienced perforation with shear punching and tearing damage are classified as either "Fail+through" or "Fail+stay". "Fail+through" means the projectile completely perforated through the specimens FSS4, FSS5 and FSS6 and flied away from them, while "Fail+stay" means the projectile perforated through the specimen but stayed in the specimen as shown in Figure 10 of FSS2. No obvious debonding between the core and skins was observed after the impact. The experimental results are summarized in Table 2.

\subsubsection{Deformation modes}


Four specimens FSS1, FSS3, FSS7 and FSS8 rejected the projectile at the back skin with no complete perforation and opening. The rebound residual velocities of FSS1, FSS3 and FSS8 obtained from the high speed camera clips are $-4.5 \mathrm{~m} / \mathrm{s},-3.8 \mathrm{~m} / \mathrm{s},-4.0 \mathrm{~m} / \mathrm{s}$, respectively. The specimens FSS1, FSS3 and FSS8 experienced different levels but similar deformation and damage profiles as shown in Figure 6 Figure 9. The projectile impact resulted in indentation and shear punching on the front skin and deformation on the back skin. Creased lines (i.e. wrinkle) extending from the impact location to the G-clamps on edges were also observed on the both skins due to the intensive stretching. The major deformation on the back skin occurred around the impact location.

As shown in Figure 10, the projectile pierced through but stayed in the specimen FSS2, which is the largest panel among all the tested panels. An initial rupture occurred at the impact area followed by tearing of the back skin. The tearing occurred when the shear strength of metal skin was exceeded. The projectile's kinetic energy was mainly absorbed by the deformation, tearing of the skins and core shear failure. As given in Table 2, the impact velocity is $18 \mathrm{~m} / \mathrm{s}$, which can be approximately considered as the velocity that just caused perforation of the panel since the projectile stayed in the panel. It is the velocity that separates the specimen FSS2 from "pass" to "fail" when it is impacted with a 4kg timber projectile.

Full length of projectile completely passed through three specimens FSS4, FSS5 and FSS6. As shown in Figure 11 Figure 13, the three specimens have similar damage and failure modes. The torn area of the front skin of the specimens FSS4 and FSS5 rebounds promptly after perforation. The specimen FSS4 with the total thickness of $50 \mathrm{~mm}$ subjected to $26 \mathrm{~m} / \mathrm{s}$ projectile impact has a smaller opening size than the identical specimen FSS5 but larger projectile residual velocity when the impact velocity is $23 \mathrm{~m} / \mathrm{s}$, indicating more direct punching shear damage of the panel when impact velocity is higher. The specimen FSS6 with a thicker total thickness of $75 \mathrm{~mm}$ has a smaller residual velocity but larger opening size and more severe damage than the specimen FSS5, which means more kinetic energy has been absorbed by the dynamic response of specimen FSS6. 


\subsubsection{Quantitative results and discussion}

Four response quantities were measured during the tests. They are opening size, residual velocity of projectile, two displacement time histories and four strain time histories on the back skin shown in Figure 4.

The specimen FSS6 experienced $1.8 \mathrm{~cm}$ peak displacement and $0.35 \mathrm{~cm}$ residual displacement at the center point on the back skin, as shown in Figure 14 (L). It is found that there is oscillation of the support frame during impact. Unfortunately, no LVDT sensor was placed to measure the vibration time hsitory of the frame. To correct the measured displacement response of the panel, the high-speed camera images were analyzed. It was found that the peak frame displacement was about $0.3 \mathrm{~cm}$. Therefore, the peak displacements are deducted by the oscillation of the support frame, which is around $0.3 \mathrm{~cm}$. The corrected results are summarized in Table 2. It should be noted that this correction is only approximate because the frame and panel responses are not necessarily exactly in phase. It is also observed that the specimens FSS1/FSS3/FSS7/FSS8 without perforation have larger residual deformation than others that the projectile penetrated through the panel. This is because larger portion of kinetic energy from the impact was taken by the skins' deformation of specimen if perforation did not occur. Figure $14(\mathrm{R})$ shows the strain time histories of specimen FSS6 after projectile impact. It can be seen that there are almost no residual strain in the four strain gauges, indicating elastic deformation in the back face metal skin. Higher peak strains around $900^{\mu \varepsilon}$ and $800^{\mu \varepsilon}$ were measured by strain gauges S1and S2 at the centre close to the impact location. Peak strains of $570 \mu \varepsilon$ and $200 \mu \varepsilon$ were captured by strain gauge S0 and S3. It should be noted that the strain gauges did not always give good measurements in the tests because some strain gauges were disconnected from the specimen due to the intensive impact load. It should also be noted that all the measured strains are relatively small, indicating small deformation at the back skin even perforation occurs. This is because perforation is a local failure of the panel owing primarily to punching shear damage. This also explains why the residual displacement of the panel is larger if the projectile did not penetrate through the panel 
as indicated in Table 2. The measured strain and displacement data will be used to calibrate the numerical model that will be developed to simulate the panel responses to timber projectile impact.

The effects of specimen size, core thickness, impact location and projectile velocity on the specimen performance were considered in the current tests. The observations and discussions are given below.

To investigate the specimen size on the panel's performance, two specimens FSS1 and FSS2with different sizes were tested. It can be found that specimen FSS2 with a doubled dimension than specimen FSS1 was perforated by the timber projectile while the specimen FSS1 survived the impact without perforation under a slightly smaller projectile impact velocity. This observation indicates that, as discussed above, penetration is a localized damage caused by brittle punching shear failure by projectile. When the projectile impact velocity is large enough to cause penetration, it absorbs significant amount of impact energy and the overall dynamic response of the panel is relative small. For the smaller panel FSS1, since the impact velocity is not big enough to cause perforation, the impact energy is therefore transferred to panel dynamic response. As a result the dynamic response of the panel (peak displacement and residual displacement, etc) is larger than that of panel FSS2 although it is stiffer than FSS2. By comparison with the damage modes of the two panels shown in Figure 6 and Figure 10, FSS1 developed obvious creased lines on both skins owing to large dynamic response which dissipated part of input energy, while no creased line was observed on panel FSS2 because penetration absorbed significant amount of impact energy.

The effect of core thickness on the panel's performance was examined by comparisons of FSS3 (core thickness 49.2mm) and FSS1 (core thickness 37.2mm), FSS5 (core thickness 49.2mm) and FSS6 (core thickness 74.2mm). The specimen FSS3 and FSS1 subjected to projectile impact at velocity of 18 $\mathrm{m} / \mathrm{s}$ and $17 \mathrm{~m} / \mathrm{s}$, respectively yield residual displacement of $0.8 \mathrm{~cm}$ and $1.4 \mathrm{~cm}$ at the impact location and residual rebound velocity of $3.8 \mathrm{~m} / \mathrm{s}$ and $4.5 \mathrm{~m} / \mathrm{s}$, respectively. These observations indicate the thicker EPS foam in FSS3 absorbed more impact energy therefore the dynamic response of the panel 
and the rebound velocity of the projectile are smaller although the impact velocity is higher than panel FSS1. As discussed above, perforation occurred in panel FSS2 when the impact velocity is $18 \mathrm{~m} / \mathrm{s}$. This indicates, as expected, increasing the foam thickness increases the panel perforation resistance capacity. Both FSS4 and FSS6 were perforated by the projectile at the velocity of $26 \mathrm{~m} / \mathrm{s}$ and $24 \mathrm{~m} / \mathrm{s}$, respectively with the residual velocity of projectile of $17 \mathrm{~m} / \mathrm{s}$ and $10 \mathrm{~m} / \mathrm{s}$, indicating increasing the panel core thickness effectively absorbs impact energy so that the residual projectile velocity is reduced. It is also interesting to note that increasing the core thickness results in a larger opening and larger dynamic response and residual displacement. This is because the larger core resistance transmits more impact energy to the panel and hence resulting in larger dynamic responses of the panel. Hoo Fatt and Park [28] found that the failure load in the analytical models depends on the type and thickness of the face skin and yield strength of the core, but not the thickness of the core. This conclusion is different from those observed in the tests, which indicate that increasing the core thickness changes the panel perforation resistance capacity and dynamic responses under projectile impact. However, it is believed the thickness of the face skin and the yield strength of the core are both critical parameters of the panel capacity to resist impact load as concluded in [28]. These parameters are not included in the tests since the current study concerns primarily the panels that are most commonly used in the construction industry. Increasing the skin thickness and/or use denser EPS foam could be an option in the future panel design to increase its impact resistance capacity although both of these options increase the weight of the panel. This will be our study in the next stage.

To examine the effect of various impact locations on the panel's performance, the specimen FSS7 was impacted by the projectile at the quarter location while an identical panel FSS6 was impacted at the centre location by the projectile with the same impact velocity of $24 \mathrm{~m} / \mathrm{s}$. Specimen FSS7 rejected the projectile while FSS6 was perforated by the projectile. This is probably because the boundary of FSS7 was pulled out from the anchor by the impact force as shown in Figure 9. Damage of the panel boundary dissipated large amounts of impact energy, therefore alleviated impact energy to 
penetrate into the panel. This observation indicates the significant effect of boundary conditions on the panel responses. However, it should be noted that damage of the boundary may also create an opening that makes the panel fail to meet the design requirement.

The influence of projectile velocity on the panel performance is significant, as expected. The specimen FSS3 rejected the projectile at the velocity of $18 \mathrm{~m} / \mathrm{s}$ while the identical specimen FSS5 was perforated by the projectile impact at $23 \mathrm{~m} / \mathrm{s}$. The specimen FSS4 subjected to $26 \mathrm{~m} / \mathrm{s}$ projectile impact created larger opening than the specimen FSS5. Similarly, the specimen FSS8 rejected the projectile at the speed of $18 \mathrm{~m} / \mathrm{s}$ while the specimen FSS6 was perforated at the velocity of $24 \mathrm{~m} / \mathrm{s}$.

\section{Numerical simulations}

The laboratory tests are numerically simulated by using LS-DYNA. The accuracy and reliability of the numerical model is validated by comparing the numerical and experimental data. In this section, the specimen FSS6 with core of thickness $74.2 \mathrm{~mm}$, skins of $0.4 \mathrm{~mm}$ and dimension of $762 \mathrm{~mm}$ by $1200 \mathrm{~mm}$ is selected to calibrate the numerical model. The failure modes and the structural responses including opening size, residual projectile velocity, displacement and strain are used to examine the accuracy of numerical simulations.

\subsection{Model calibration and validation}

\subsubsection{Element and mesh convergence study}

The numerical models are created by using commercial software ANSYS and LS-PREPOST. The finite element model of the specimen is depicted in Figure 15 (L). The Belytschko-Tsay shell element [36] is used to model the both skins. The shell element with 5 integration points overcomes the lack of elements through the thickness direction. EPS core is meshed by using eight node solid element with single integration points (i.e. ELFORM=1, constant stress solid elements) to overcome the negative volume, which is prone to happen in full integration elements. To avoid the negative volume, hourglass control with assumed strain co-rotational stiffness form (i.e. IHQ=6) is used. The 
timber projectile of mass $4 \mathrm{~kg}$, $900 \mathrm{~mm}$ length and cross-section of $100 \mathrm{~mm}$ by $50 \mathrm{~mm}$ is built using eight node solid elements. As the hardwood projectile experienced no obvious deformation and mass loss after the tests, the timber projectile is modeled as linear elastic material *MAT ELASTIC. The density and Young's modulus are $888 \mathrm{~kg} / \mathrm{m}^{3}$ and $10 \mathrm{GPa}$, respectively. In the test the projectile was aimed to head-on impact at the center of the specimen. However, the actual impact point in the testing was of a small distance away from the center point and the projectile rotated and the impact angle was not exactly $90^{\circ}$ owing to the gravity load on the projectile when flying the $3 \mathrm{~m}$ distance from the cannon exit to the panel as shown in Figure $15(\mathrm{R})$. In this study, to more accurately simulate the impact scenario in the test, full model of specimen with flying projectile are modeled, instead of starting the simulation when projectile is in contact with the panel.

The simulation result is sensitive to mesh size. In general, finer mesh size yield more accurate results but increases the simulation time. Convergence study is carried out by halving the mesh size. Three element sizes of $10 \mathrm{~mm}, 5 \mathrm{~mm}$ and $2.5 \mathrm{~mm}$ are used in the region of impact where dense elements are applied as shown in Figure 15. Other region uses 10mm mesh size. As shown in Table 3 and Figure 16, numerical results show the predicted residual projectile velocity by using $10 \mathrm{~mm}$ mesh size is underestimated while both $5 \mathrm{~mm}$ and $2.5 \mathrm{~mm}$ yield close results to the actual projectile residual velocity of $10 \mathrm{~m} / \mathrm{s}$ recorded in the test. Further reduce mesh size only has insignificant influence on numerical results but leads to a substantial increase in computational time. To save calculation time, $5 \mathrm{~mm}$ mesh size is utilized in the dense area in the subsequent simulations.

\subsubsection{Boundary conditions and contact}

Properly modeling the boundary condition is critical to achieve the reasonable numerical result. In this study, the specimen was clamped on the support frame by using G-clamps along four sides. In the numerical model, to reduce the modeling effort the specimen is assumed constrained on the three DOFs of UX, UY and UZ at the four edges by using *BOUNDARY SPC SET, closely approximating the boundary conditions in the test. 
The contact between the projectile and the specimen is defined by using *CONTACT ERODING SURFACE TO SURFACE with segment based contact option (i.e. SOFT=2). Scale factors on penalty stiffness (i.e SFS and SFM) are increased to avoid the excessive penetration of the slave part into master part. To account for the contact between skins and cores, *CONTACT ERODING SINGLE SURFACE is used and *CONTACT INTERIOR is utilized to avoid the negative volume within the EPS core. Debonding between the skins and the core is not obvious in the tests. Therefore, the adhesive effect is not considered in the numerical simulation and the constraints are applied between two skins and the core.

\subsubsection{Material model}

The elastic-plastic material model *MAT PLASTIC KINETIC in LS-DYNA is adopted to model the cold rolled stainless steel. It is suitable for modeling the bi-linear elastic-plastic constitutive relation of metals with isotropic kinetic hardening plasticity. The input parameters defined in this material model are based on the quasi-static material testing. The strain rate effect is taken into account by using Cowper-Symonds model available in LS-DYNA as defined in Eq.(1). It is commonly used to simulate the strain rate effect of structure steels.

$$
\frac{\sigma_{d}}{\sigma_{s}}=1+\left(\frac{\dot{\varepsilon}}{C}\right)^{1 / p}
$$

where $\sigma_{d}$ is the dynamic flow stress at plastic strain rate $\dot{\varepsilon}, \sigma_{s}$ is the associated static flow stress, the strain rate parameters $\mathrm{C}$ (Cowper constant) and $\mathrm{P}$ (Symonds constant) are $100 \mathrm{~s}^{-1}$ and 10 , respectively based on test results. The material properties used in the calculation are given in Table 4.

EPS is a material with complex behaviors under stress. The compressive stress-strain curve of EPS can be divided into three zones, i.e. elastic region, plateau compaction region and densification region. It has been found that density affects the mechanical properties of EPS. With the increase of density, compressive elastic modulus and yield strength increase. Therefore, the material constitutive models should be selected appropriately. In LS-DYNA[39], there are some material models available 
for modeling a wide variety of polymer foams, such as *Mat Low Density Foam (57\#), *Mat Crushable Foam (63\#), *Mat Fu Chang (83\#), *Mat Modified Crushable Foam (163\#), which are relatively simple to calibrate and reproduce the behaviors of foams. Because EPS exhibits rate dependency in testing, the material model *Mat Modified Crushable Foam (163\#), which incorporates the strain rate effect into the material model *Mat Crushable Foam, is ideal for EPS core [40]. The material properties of EPS with density of $13.5 \mathrm{~kg} / \mathrm{m}^{3}$ are given as follows. E=900kPa; Poisson's ratio $=0 ; \mathrm{Tc}=40 \mathrm{kPa} ; \mathrm{Damp}=0.4$. Because of the lack of some material properties, available test data of similar EPS material properties are adopted in this study. In particular the stress-volumetric strain curve used is based on the data for EPS with density of $16 \mathrm{~kg} / \mathrm{m}^{3}$, as shown in Figure 17 [40]. Although it is believed that the material properties of EPS with density $16 \mathrm{~kg} / \mathrm{m}^{3}$ and $13.5 \mathrm{~kg} / \mathrm{m}^{3}$ would be very similar, further study of material properties is necessary to confirm this assumption. Nevertheless, the present numerical model with the stress-strain curves given in Figure 17 successfully predicts the failure modes and structural responses of the tested panels.

To predict the penetration of specimen under projectile impact, selection of an erosion criterion is important. Erosion technique is used in the simulation to model damage or penetration. However, it is to be noted that erosion technique is a numerical manipulation in finite element simulation of large deformations. It is used in the study to simulate damage and failure to avoid mesh tangling. In the present study, the mass of deleted elements is retained in the simulation so as to maintain mass conservation. In LS-DYNA the maximum principle stress, plastic volumetric strain and the maximum shear strain can be used as erosion criterion. In this study, the maximum shear strain and the failure strain of the plastic kinematic constitutive model are used to define the erosion criterion of EPS core and skins, respectively. After extensive trial and error, the maximum shear strain (MSS) at failure is taken as 0.04 for EPS and the failure strain (FS) of steel is defined as 0.045 .

\subsection{Comparison of experimental and numerical results}

Figure 18 shows the numerical prediction of damage mode of specimen FSS6 after the projectile 
impact. The opening size obtained in the numerical analysis is $17.2 \times 14.5 \mathrm{~mm}$, comparable to $17.0 \times 15.5 \mathrm{~cm}$ obtained in the experimental test. The LVDT measures time histories of two locations. The residual velocity retrieved from the numerical results is $10.9 \mathrm{~m} / \mathrm{s}$ which is closed to $10.0 \mathrm{~m} / \mathrm{s}$ measured in the test.

Figure 19 shows the comparison of the experimental and numerical displacement time histories at two locations for specimen FSS6. It should be noted that, as discussed above, during the test, small vibration of the supporting frame was observed. The LVDT measured peak panel displacements were thereby deducted by $0.3 \mathrm{~cm}$ of the support frame displacement. It should be noted that this correction is only approximate since the frame vibration was not necessarily in-phase with the panel vibration. Unfortunately the frame vibration was not measured in the test. Table 5 compares the predicted and the measured maximum displacements. The errors at the two measurement locations are about $5.9 \%$ and $6.5 \%$, respectively. Numerical simulation also gives good predictions of strain time histories at the four locations as shown in Figure 20. As given in Table 6, the differences of the peak stains of the four strain gauges are around $11.7 \%, 9.6 \%, 10.8 \%$ and $0.9 \%$, respectively. These errors are considered small and acceptable because of the unavoidable numerical errors. Through comparison of numerical results and testing results, it can be concluded that the numerical model gives reasonably accurate predictions of the panel responses to the projectile impact. The calibrated numerical model will be used to calculate the penetration resistant capacity of the panel subjected to windborne debris impact.

Figure 21 shows the Von mises stress distributions in the both skins. It can be seen that high stress occurs around the perforated hole on both skins. High stress also appears along the latitude line of the front skin due to the intensive stretching. As shown in Figure 22, the kinetic energy of 1152J from the projectile was reduced to $276 \mathrm{~J}$ after penetration. The input energy from the projectile is absorbed in the forms of the penetration and deformation of the core and the two skins, as well as the vibration of the panel and the support frame. Table 7 shows the partitions of energy absorption by the skins and EPS. The two skins and the EPS core respectively absorb $19.9 \%$ and $32.6 \%$ of the total 
energy in the forms of deformation, rupture and shear damage. The sliding energy dissipated by the friction action also accounts for $22.2 \%$ of the total absorbed energy. The numerical simulated impact force time history by the projectile is shown in Figure 23. The projectile impacting the front skin results in a peak force around $15 \mathrm{kN}$. The second peak of $11.9 \mathrm{KN}$ occurs when the projectile hits the back skin.

\subsection{Vulnerability curve}

In this section, a composite SIP with EPS core of thickness $74.2 \mathrm{~mm}$, skins of $0.4 \mathrm{~mm}$ and dimension of $762 \mathrm{~mm}$ by $1200 \mathrm{~mm}$ is analyzed to examine its vulnerabitity to windborne debris impact. The timber projectile weighing $1 \mathrm{~kg}, 2 \mathrm{~kg}, 4 \mathrm{~kg}, 6 \mathrm{~kg}$ and $8 \mathrm{~kg}$ are considered. The projectile velocity varies from $15 \mathrm{~m} / \mathrm{s}$ required in the 2002 version of the Australian Wind Loading standard, to $40 \mathrm{~m} / \mathrm{s}$, which is about the highest debris travelling speed specified in cyclone areas [1].

Table 8 summarizes the numerical results, i.e. thresholds of the combinations of debris mass and velocity to perforate the panel, where "P" represents perforation and "N" stands for no perforation. Table 9 gives the threshold kinetic energy of projectile under varied mass. It is found that the panel is more prone to be perforated by the projectile with lighter but higher speed at the same impact kinetic energy and momentum. For instance, the panel rejected the $8 \mathrm{~kg}$ projectile travelling at $15 \mathrm{~m} / \mathrm{s}$ but perforated by $2 \mathrm{~kg}$ projectile traveling at $30 \mathrm{~m} / \mathrm{s}$ with identical kinetic projectile energy of $900 \mathrm{~J}$. This is because the faster is the impact, the less ductile the panel is. Therefore, it can be concluded that the penetration resistance capacity of the panel cannot be only determined by either impact kinetic energy or impact momentum. Both the projectile mass and impact velocity play important roles in the penetration resistant capacity.

As shown in Figure 24, a perforation vulnerability curve is created with respect to projectile mass and impact velocity. The occurrence of perforation of the panel is divided by the curve. No perforation occurs when the combination of velocity and mass is on the left and below the curve while perforation occurs when it is on the right and above the curve. With higher velocity and larger mass, 
the debris is more likely to penetrate the panel as expected. This vulnerability curve might be useful for the assessment and design of the composite SIP against the windborne debris impact.

\section{Conclusions}

In this study, laboratory tests on eight composite SIPs with EPS core against windborne debris impact were carried out by using pneumatic cannon testing system. The deformation profiles of specimens were examined and discussed. Most of the penetrated specimens show shear punching and tearing failure. The penetration resistance, opening size, residual velocity of projectile after perforation or rebound, displacement and strain time histories at some representative points on the panel back skin were recorded. The effects of the specimen dimension, impact location and debris impact velocity on the penetration resistant capacity against windborne debris impact were identified based on experimental tests. In addition, a numerical model was also developed by using LS-DYNA. The validity of the numerical model was calibrated with the testing results. Using the calibrated model, the energy absorption and impact force of panels subjected to projectile impacts have been examined. Vulnerability curve of a typical SIP panel against windborne debris impact was generated. The vulnerability curve might find applications in assessment and design of SIP panel against windborne debris impact. It is noted that all the tested specimens could not pass the test if they were subjected to a timber rod impact at velocity $26 \mathrm{~m} / \mathrm{s}$, which is below the required windborne debris impact resistance capacity for structural panels in some regions defined in the Australian Standard [1].

\section{Acknowledgments}

The authors acknowledge the financial support from Australian Commonwealth Scientific and Industrial Research Organization (CSIRO) through the project "Climate Adaptation Engineering for Extreme Events Cluster". The authors acknowledge Mr. Naz Merai from Azuma Design, Mr. Michael Augustson, Mr. Mingyang Zhou and Mr. Jim Walters for their assistance in the lab. 


\section{References}

[1] AS/NZS. Structural design actions. Part2: Wind actions. Sydney, NSW, Australia: Standard Australia \& Standards New Zealand; 2011.

[2] Rappaport E. Preliminary Report (updated 2 March 1993) Hurricane Andrew, 16-28 August 1992: National Hurricane Center; 1993.

[3] Minor JE. Lessons learned from failures of the building envelope in windstorms. J Archit Eng. 2005;11:10.

[4] Wills J, Lee B, Wyatt T. A model of wind-borne debris damage. J Wind Eng Ind Aerod. 2002;90:555-65.

[5] McDonald JR. Impact resistance of common building materials to tornado missiles. J Wind Eng Ind Aerod. 1990;36:717-24.

[6] Minor JE, Mehta KC, McDonald JR. Failure of structures due to extreme winds. Journal of the Structural Division. 1972;98:2455-71.

[7] Tamura Y. Wind induced damage to buildings and disaster risk reduction. Proceedings of the APCWE-VII, Taipei, Taiwan. 2009.

[8] A Summary Report on Debris Impact Resistance of Building Assemblies. Texas Tech University etc.; 2006.

[9] FEMA. Design and Construction Guidance for Community Safe Rooms (FEMA P-361 Second Edition). USA: Federal Emergency Management Agency; 2008.

[10] FBC. Florida Building Code 2010, Building. USA: International Code Council, Inc.; 2011.

[11] ASTM. Standard Specification for Performance of Exterior Windows, Curtain Walls, Doors and Storm Shutters Impacted by Windborne Debris in Hurricanes. West Conshohocken, PA, USA: American Society for Testing and Materials; 2009.

[12] SBC. Standard for Determining Impact Resistance from Windborne Debris. Birmingham, Alabama, USA: Southern Building Code Congress International; 1999.

[13] FEMA. Taking Shelter From the Storm: Building a Safe Room For Your Home or Small Business (FEMA P-320 Third Edition). USA: Federal Emergency Management Agency; 2008.

[14] Department of public works. Design guidelines for queensland public cyclone shelters. Queensland government. 2006. 
[15] Mousa MA, Uddin N. Global buckling of composite structural insulated wall panels. Mater Des. 2011;32:766-72.

[16] Smakosz L, Tejchman J. Evaluation Of Strength, Deformability And Failure Mode Of Composite Structural Insulated Panels. Mater Des. 2013.

[17] Chen W, Hao H. Experimental investigations and numerical simulations of multi-arch double-layered panels under uniform impulsive loadings. Int J Impact Eng. 2013.

[18] Zhang X, Hao H, Ma G. Laboratory test and numerical simulation of laminated glass window vulnerability to debris impact. Int J Impact Eng. 2013;55:49-62.

[19] Xu Z, Hao H, Li H. Experimental study of dynamic compressive properties of fibre reinforced concrete material with different fibres. Mater Des. 2012;33.

[20] Zhao H, Elnasri I, Girard Y. Perforation of aluminium foam core sandwich panels under impact loading_-An experimental study. Int J Impact Eng. 2007;34:1246-57.

[21] Børvik T, Langseth M, Hopperstad O, Malo K. Perforation of $12 \mathrm{~mm}$ thick steel plates by $20 \mathrm{~mm}$ diameter projectiles with flat, hemispherical and conical noses: part I: experimental study. Int J Impact Eng. 2002;27:19-35.

[22] Scheer DL. Large wind missile impact performance of public and commercial building assemblies: Florida State University; 2005.

[23] Braden CP. Large wind missile impact performance of public and commercial building assemblies: University of Florida; 2004.

[24] Corbett G, Reid S, Johnson W. Impact loading of plates and shells by free-flying projectiles: a review. Int J Impact Eng. 1996;18:141-230.

[25] Backman ME, Goldsmith W. The mechanics of penetration of projectiles into targets. IJES. 1978;16:1-99.

[26] Børvik T, Langseth M, Hopperstad O, Malo K. Ballistic penetration of steel plates. Int J Impact Eng. 1999;22:855-86.

[27] Mohotti D, Ngo T, Mendis P, Raman SN. Polyurea coated composite aluminium plates subjected to high velocity projectile impact. Mater Des. 2013;52:1-16.

[28] Hoo Fatt MS, Park KS. Dynamic models for low-velocity impact damage of composite sandwich panels-Part B: Damage initiation. Compos Struct. 2001;52:353-64. 
[29] Hoo Fatt MS, Park KS. Dynamic models for low-velocity impact damage of composite sandwich panels - Part A: Deformation. Compos Struct. 2001;52:335-51.

[30] Zhu F, Lu G, Ruan D, Wang Z. Plastic Deformation, Failure and Energy Absorption of Sandwich Structures with Metallic Cellular Cores. Int J Protective Struct. 2010;1:507-41.

[31] Knight N, Jaunky N, Lawson RE, Ambur DR. Penetration simulation for uncontained engine debris impact on fuselage-like panels using LS-DYNA. Finite Elem Anal Des. 2000;36:99-133.

[32] Ozturk UE, Anlas G. Finite element analysis of expanded polystyrene foam under multiple compressive loading and unloading. Mater Des. 2011;32:773-80.

[33] Technical data Foamex Styroboard EPS, www.foamex.com.au. Retrieved on $18^{\text {th }}$ Sep, 2013.

[34] Technical data (Suprasec 7113) Huntsman, www.huntsman.com. Retrieved on $22^{\text {nd }}$ Sep, 2013.

[35] National-Instruments, http://australia.ni.com. Retrieved on $1^{\text {st }}$ Sep, 2013.

[36] Hallquist JO. Ls-Dyna ${ }^{\circledR}$ Theory Manual. Livermore Software Technology Corporation: Livermore. 2006.

[37] Rogers CA, Hancock GJ. Ductility of G550 sheet steels in tension-elongation measurements and perforated tests. Sydney University; 1996.

[38] Technical data Versiclad, www.versiclad.com.au. Retrieved on $21^{\text {st }}$ Sep, 2013.

[39] (LSTC) LSTC. LS-DYNA® KEYWORD USER'S MANUAL Version 971. 2007.

[40] Croop B, Lobo H. Selecting material models for the simulation of foams in LS-DYNA. Proceedings of 7th European LS-DYNA Conference. Salzburg2009. 
Table 1 Specifications of specimens and testing scheme

\begin{tabular}{|c|c|c|c|c|c|c|}
\hline Specimen & Impact location & Projectile velocity $(\mathrm{m} / \mathrm{s})$ & Dimension(m) & Total thickness & $\begin{array}{c}\begin{array}{c}\text { Thickness of } \\
\text { skins }\end{array} \\
\end{array}$ & Weight $(\mathrm{kg})$ \\
\hline FSS1 & center & 17 & $1.2 \times 0.762$ & $38 \mathrm{~mm}$ & $0.4 \mathrm{~mm}$ & 6.8 \\
\hline FSS2 & center & 18 & $1.2 \times 1.4$ & $38 \mathrm{~mm}$ & $0.4 \mathrm{~mm}$ & 13.6 \\
\hline FSS3 & center & 18 & $1.2 \times 0.762$ & $50 \mathrm{~mm}$ & $0.4 \mathrm{~mm}$ & 7.0 \\
\hline FSS4 & center & 26 & $1.2 \times 0.762$ & $50 \mathrm{~mm}$ & $0.4 \mathrm{~mm}$ & 7.0 \\
\hline FSS5 & center & 23 & $1.2 \times 0.762$ & $50 \mathrm{~mm}$ & $0.4 \mathrm{~mm}$ & 7.0 \\
\hline FSS6 & center & 24 & $1.2 \times 0.762$ & $75 \mathrm{~mm}$ & $0.4 \mathrm{~mm}$ & 7.2 \\
\hline FSS7 & quarter & 24 & $1.2 \times 0.762$ & $75 \mathrm{~mm}$ & $0.4 \mathrm{~mm}$ & 7.2 \\
\hline FSS8 & center & 18 & $1.2 \times 0.762$ & $75 \mathrm{~mm}$ & $0.4 \mathrm{~mm}$ & 7.2 \\
\hline
\end{tabular}


Table 2 Specimen configurations and test results

\begin{tabular}{|c|c|c|c|c|}
\hline \multirow{2}{*}{ Specimen } & Penetration status & Front opening size $(\mathrm{cm})$ & $\begin{array}{c}\text { Residual Velocity } \\
(\mathrm{m} / \mathrm{s})\end{array}$ & Residual displacement (cm) \\
\hline FSS1 & Pass & $13 \times 6$ (ruptured $)$ & -4.5 & 0 \\
\hline FSS2 & Fail+stay & $15 \times 6$ & -3.8 & 1.5 \\
\hline FSS3 & Pass & $13 \times 13$ (ruptured) & 17.0 & 0.1 \\
\hline FSS4 & Fail+through & $14 \times 6$ & 15.0 & 0.1 \\
\hline FSS5 & Fail+through & $16.5 \times 11.5$ & 10.0 & 0.1 \\
\hline FSS6 & Fail+through & $17 \times 15.5$ & - & 0.7 \\
\hline FSS7 & Pass & - & -4.0 & 3.3 \\
\hline FSS8 & Pass & $15 \times 13$ (ruptured) & & 1.0 \\
\hline
\end{tabular}


Table 3 Results of convergence test

\begin{tabular}{|c|c|c|}
\hline Mesh size & Elements & $\begin{array}{c}\text { Residual } \\
\text { velocity }(\mathrm{m} / \mathrm{s})\end{array}$ \\
\hline $2.5 \mathrm{~mm}$ & 673,344 & 12.4 \\
\hline $5 \mathrm{~mm}$ & 128,536 & 10.9 \\
\hline $10 \mathrm{~mm}$ & 19,296 & 0 \\
\hline Testing & - & 10.0 \\
\hline
\end{tabular}


Table 4 Material properties of Zincalume AZ150 G300 steel [37, 38]

\begin{tabular}{ccccccc}
$\begin{array}{c}\text { Young's } \\
\text { Modulus }\end{array}$ & Poisson's Ratio & Yield Stress & $\begin{array}{c}\text { Thickness } \\
\text { (B.M.T) }\end{array}$ & Density & $\begin{array}{c}\text { Hardening } \\
\text { Parameter, } \beta\end{array}$ & C \\
\hline $220 \mathrm{GPa}$ & 0.3 & $330 \mathrm{MPa}$ & $0.40 \mathrm{~mm}$ & $7850 \mathrm{Kg} / \mathrm{m}^{3}$ & 0 & $100 \mathrm{~s}^{-1}$ \\
\hline Note: B.M.T.=material properties based on the base material thickness & & 0.045 \\
\hline
\end{tabular}

Note: B.M.T.=material properties based on the base material thickness 
Table 5 Experimental and numerical results of residual velocity, opening size and peak displacement.

\begin{tabular}{|c|c|c|c|c|c|c|c|c|c|c|}
\hline Specimen & Test & Numerical & Test & Numerical & Test & Numerical & Error & Test & Numerical & Error \\
\hline
\end{tabular}


Table 6 Experimental and numerical results of strain

\begin{tabular}{|c|c|c|c|c|c|c|c|c|c|c|c|c|}
\hline \multirow[t]{2}{*}{ Specimen } & \multicolumn{3}{|c|}{ Peak Strain $0(\mu \varepsilon)$} & \multicolumn{3}{|c|}{ Peak Strain $1(\mu \varepsilon)$} & \multicolumn{3}{|c|}{ Peak Strain $2(\mu \varepsilon)$} & \multicolumn{3}{|c|}{ Peak Strain $3(\mu \varepsilon)$} \\
\hline & Test & NS & Error & Test & NS & Error & Test & NS & Error & Test & NS & Error \\
\hline
\end{tabular}


Table 7 Energy absorptions by the specimen

\begin{tabular}{|c|c|c|c|c|}
\hline & Erode Energy $(\mathrm{J})$ & Internal Energy $(\mathrm{J})$ & Total Energy $(\mathrm{J})$ & Percentage \\
\hline Front Skin & 36 & 91 & 127 & $11.6 \%$ \\
\hline Back Skin & 27 & 64 & 91 & $8.3 \%$ \\
\hline EPS & 97 & 259 & 356 & $32.6 \%$ \\
\hline Sliding energy by friction & - & - & 242 & $22.2 \%$ \\
\hline Projectile Residual Kinetic Energy & & & $25.3 \%$ \\
\hline
\end{tabular}


Table 8 Penetration with respect to the projectile mass and velocity

\begin{tabular}{|c|c|c|c|c|c|c|c|c|c|c|c|c|c|c|}
\hline & & \multicolumn{13}{|c|}{ Velocity $(\mathrm{m} / \mathrm{s})$} \\
\hline & & 15 & 17 & 18 & 19 & 20 & 21 & 22 & 25 & 27 & 30 & 35 & 36 & 40 \\
\hline \multirow{3}{*}{ Mass } & $2 \mathrm{~kg}$ & $\mathrm{~N}$ & $\mathrm{~N}$ & $\mathrm{~N}$ & $\mathrm{~N}$ & $\mathrm{~N}$ & $\mathrm{~N}$ & $\mathrm{~N}$ & $\mathrm{~N}$ & $\underline{\mathrm{N}}$ & $\mathrm{P}$ & $\mathrm{P}$ & $\mathrm{P}$ & $\mathrm{P}$ \\
\hline & $6 \mathrm{~kg}$ & $\mathrm{~N}$ & $\mathrm{~N}$ & $\mathrm{~N}$ & $\underline{N}$ & $\mathrm{P}$ & $\mathrm{P}$ & $\mathrm{P}$ & $\mathrm{P}$ & $\mathrm{P}$ & $\mathrm{P}$ & $\mathrm{P}$ & $\mathrm{P}$ & $\mathrm{P}$ \\
\hline & $8 \mathrm{~kg}$ & $\mathrm{~N}$ & $\underline{\mathrm{N}}$ & $\mathrm{P}$ & $\mathrm{P}$ & $\mathrm{P}$ & $\mathrm{P}$ & $\mathrm{P}$ & $\mathrm{P}$ & $\mathrm{P}$ & $\mathrm{P}$ & $\mathrm{P}$ & $\mathrm{P}$ & $\mathrm{P}$ \\
\hline
\end{tabular}


Table 9 Threshold kinetic energy of projectile to penetrate the panel

\begin{tabular}{|c|c|c|c|c|c|c|}
\hline \multirow{2}{*}{\multicolumn{2}{|c|}{ Threshold kinetic energy }} & \multicolumn{5}{|c|}{ Projectile Velocity } \\
\hline & & $17 \mathrm{~m} / \mathrm{s}$ & $19 \mathrm{~m} / \mathrm{s}$ & $21 \mathrm{~m} / \mathrm{s}$ & $27 \mathrm{~m} / \mathrm{s}$ & $36 \mathrm{~m} / \mathrm{s}$ \\
\hline \multirow{5}{*}{ Mass } & $1 \mathrm{~kg}$ & & & & & $648 \mathrm{~J}$ \\
\hline & $2 \mathrm{~kg}$ & & & & $729 \mathrm{~J}$ & \\
\hline & $4 \mathrm{~kg}$ & & & $882 \mathrm{~J}$ & & \\
\hline & $6 \mathrm{~kg}$ & & $1083 \mathrm{~J}$ & & & \\
\hline & $8 \mathrm{~kg}$ & $1156 \mathrm{~J}$ & & & & \\
\hline
\end{tabular}




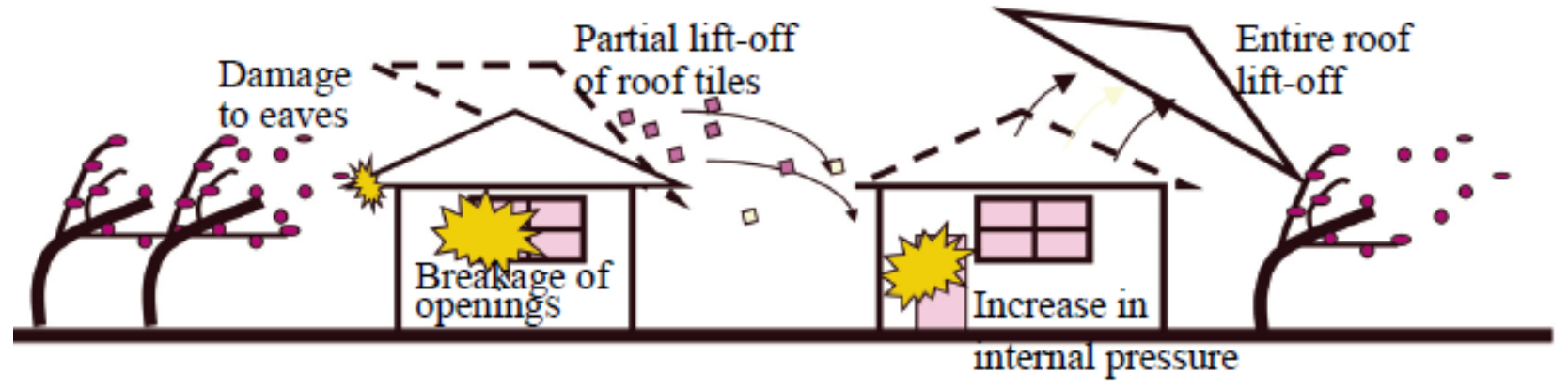

Figure 1 Illustration of possible windborne debris damage to building [7] 


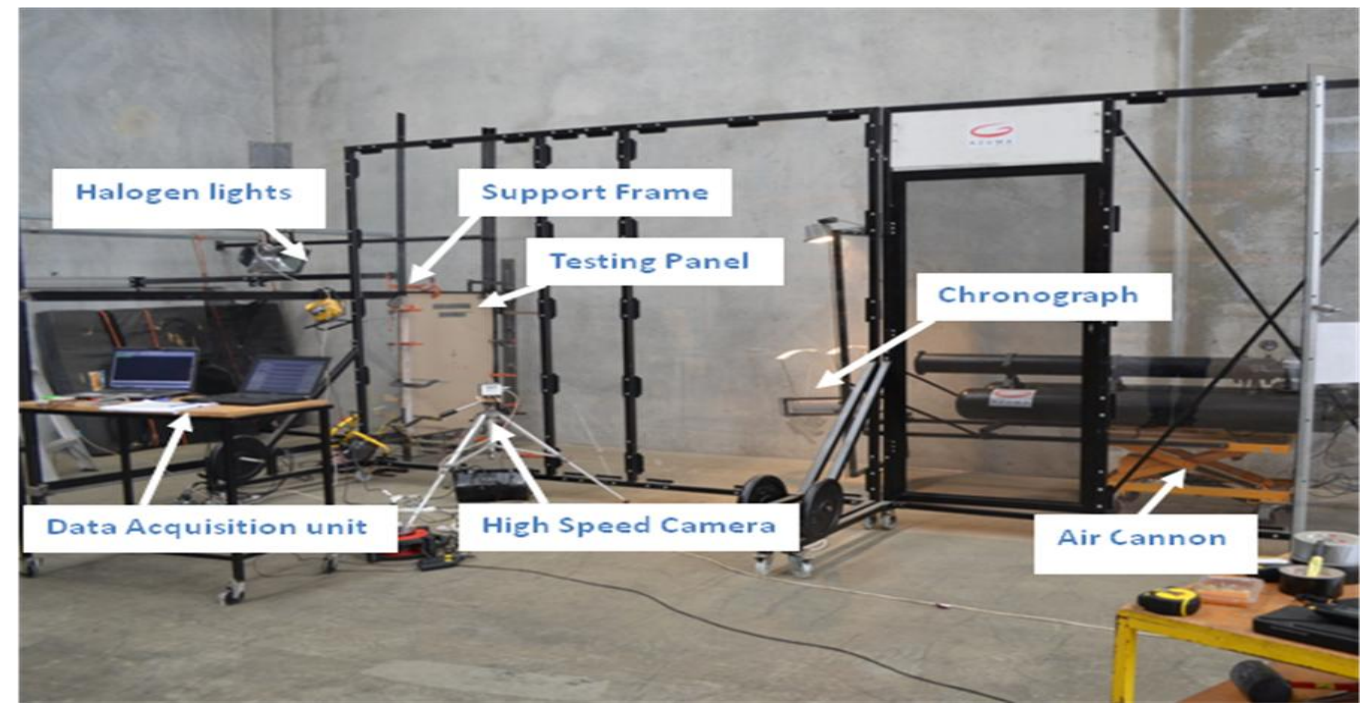

Figure 2 Experimental set-up of the overall test system 


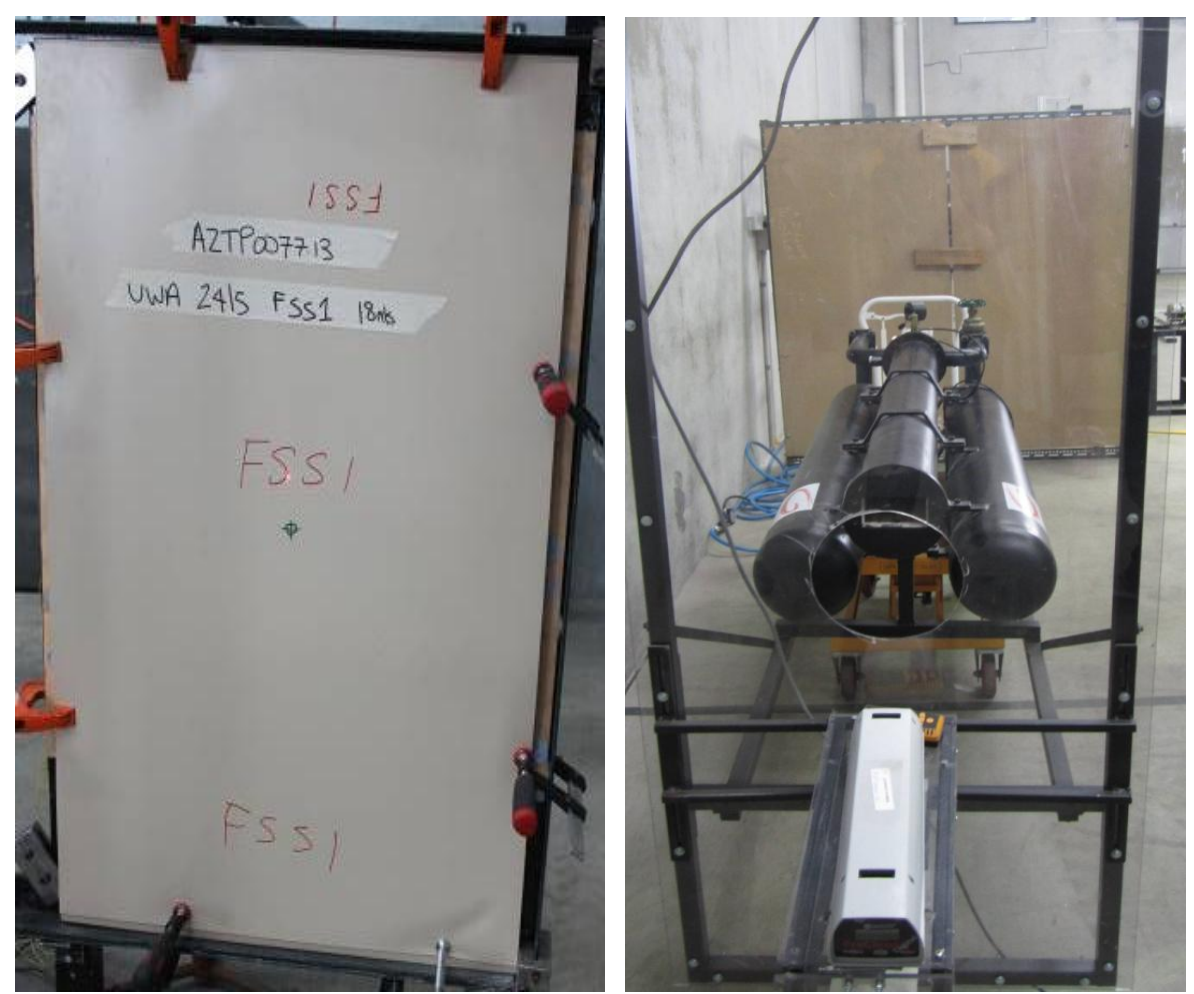

Figure 3 (L) Typical setup; (R) Pneumatic cannon 

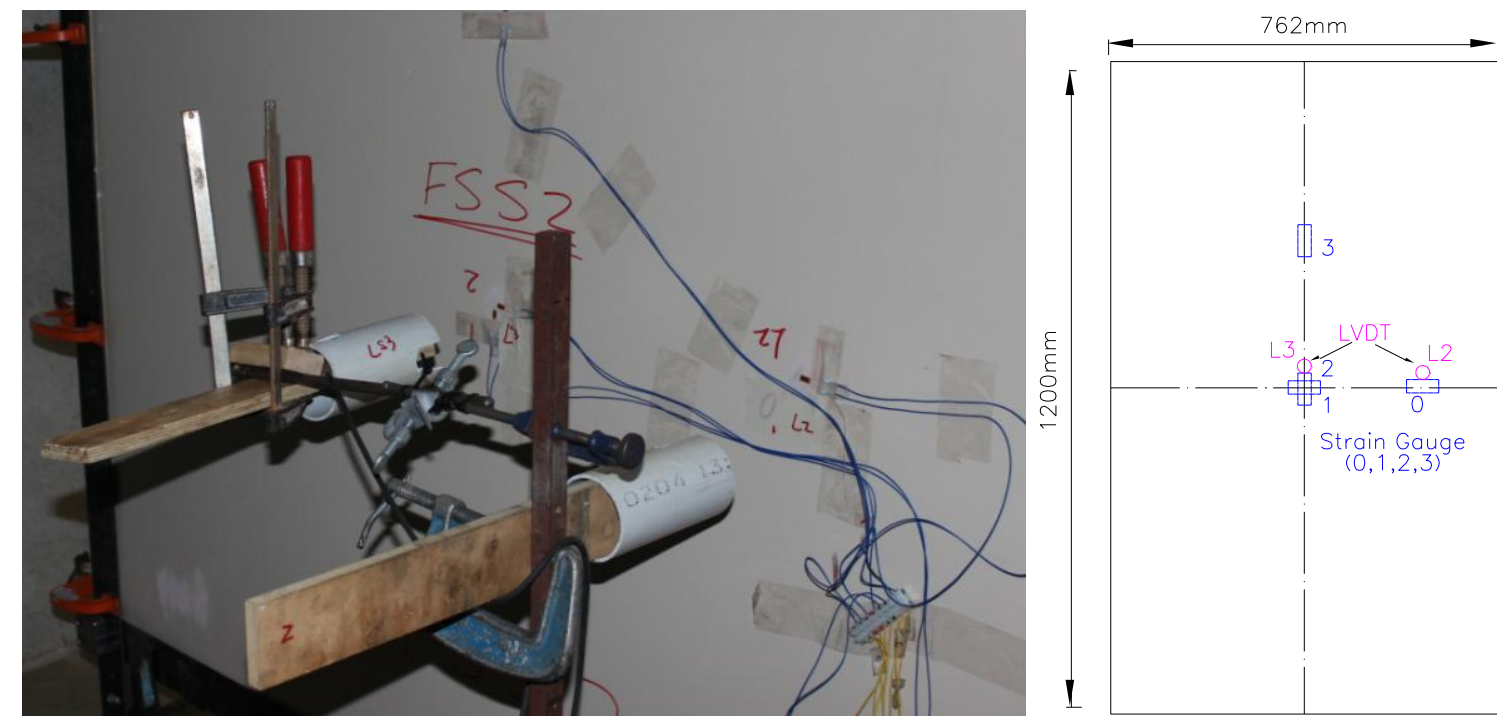

Figure 4 (L) Placement of four strain gauges and Laser LVDT on the back skin; (R) Schematic diagrams of strain gauges and LVDT placement 


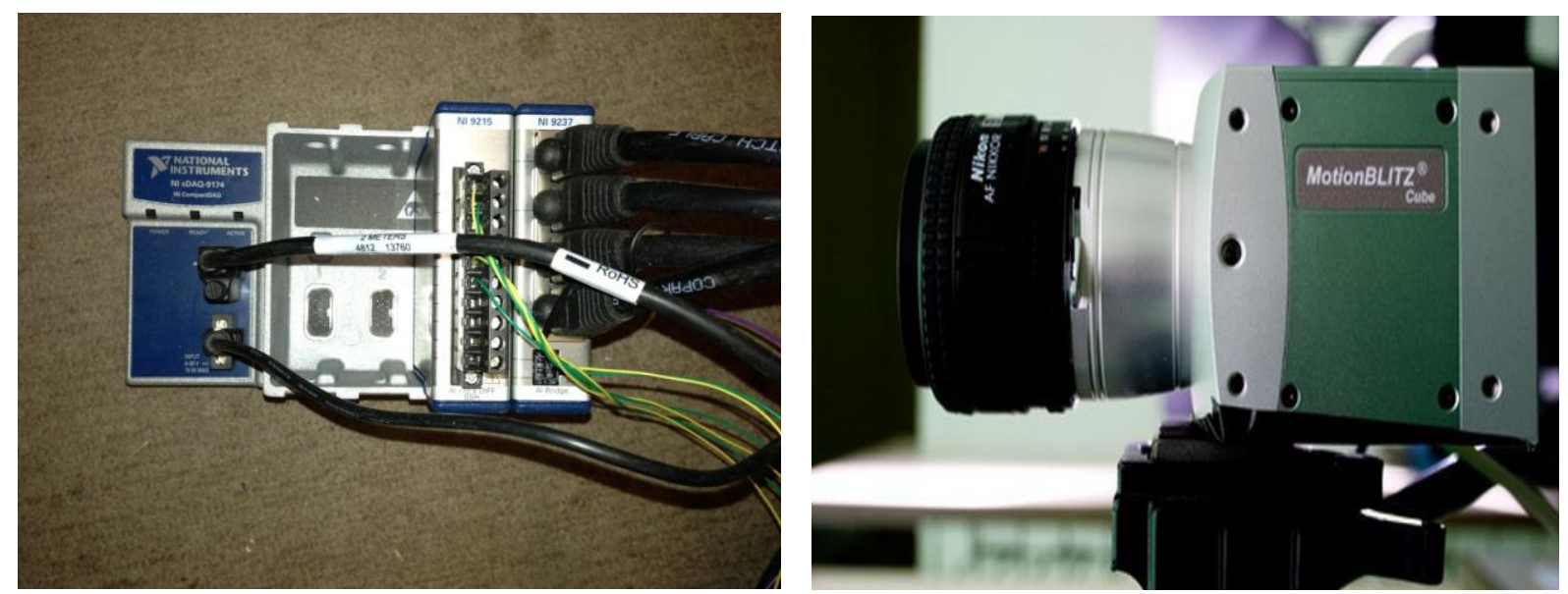

Figure 5 (L) Data Acquisition Unit by National Instruments®; (R) High-speed camera 


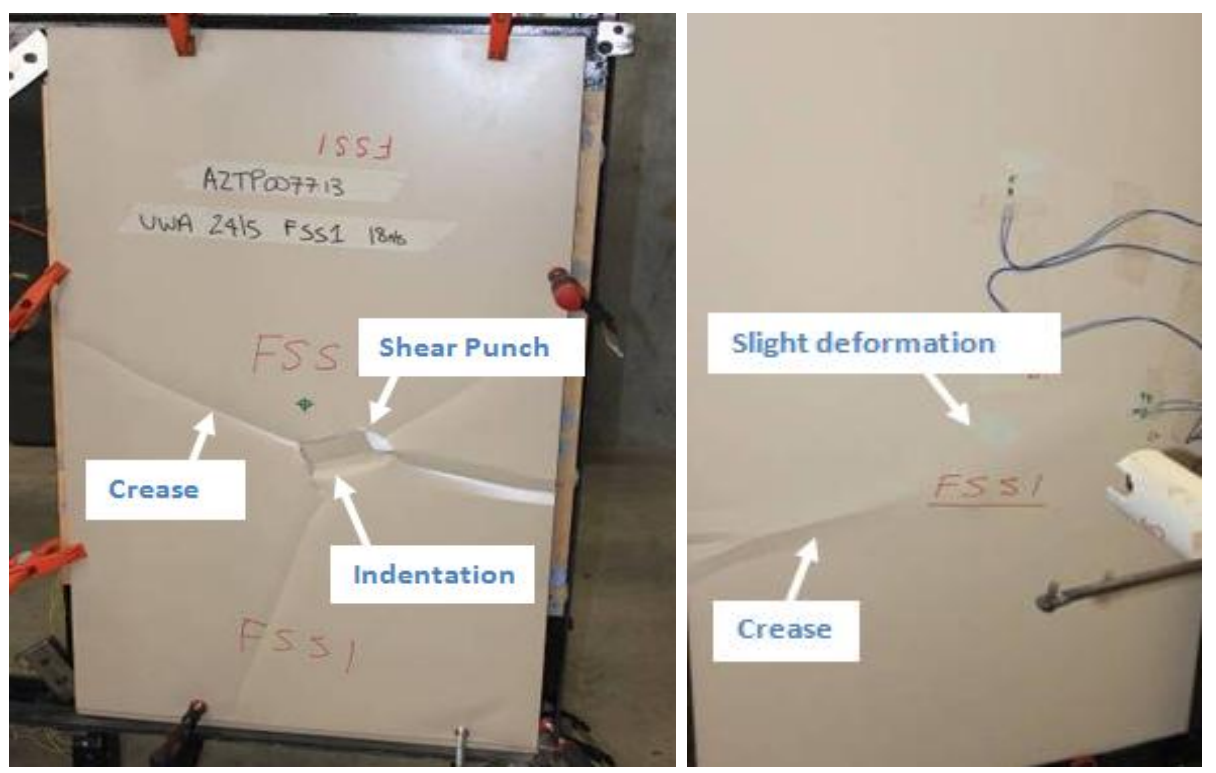

Figure 6 Photographs of specimen FSS1 (L) front view; (R) back view 


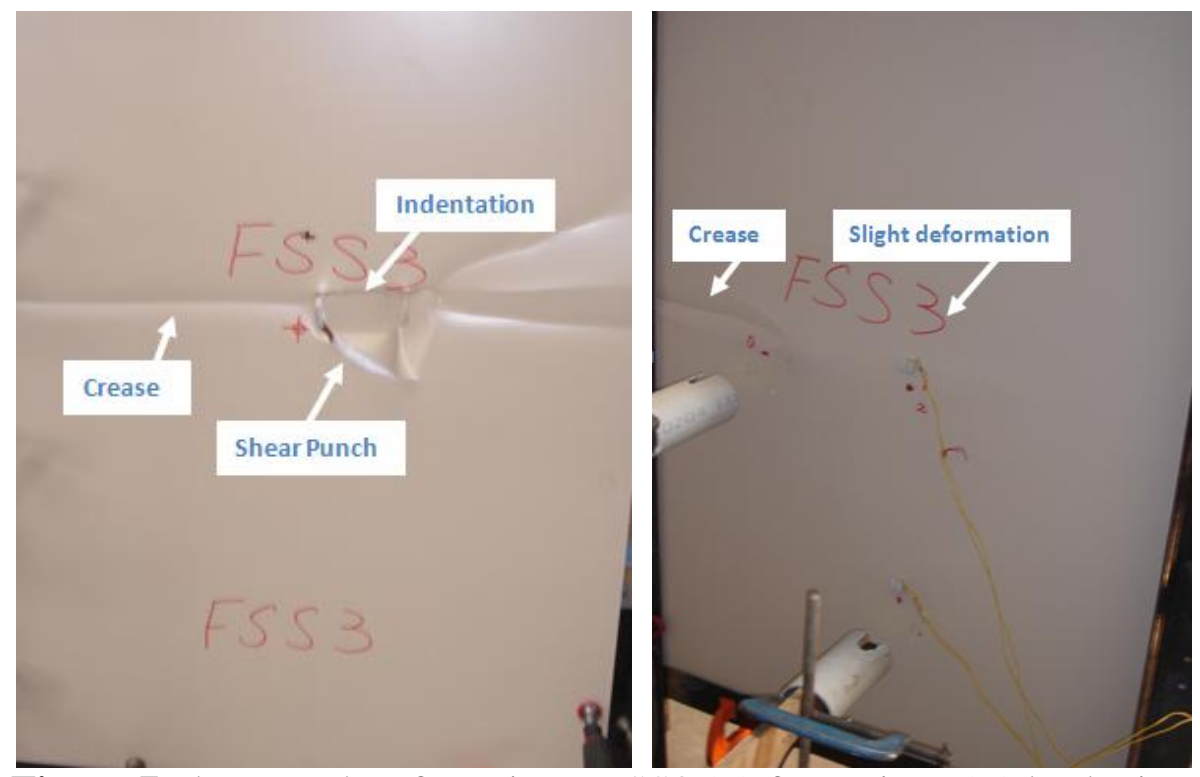

Figure 7 Photographs of specimen FSS3 (L) front view; (R) back view 


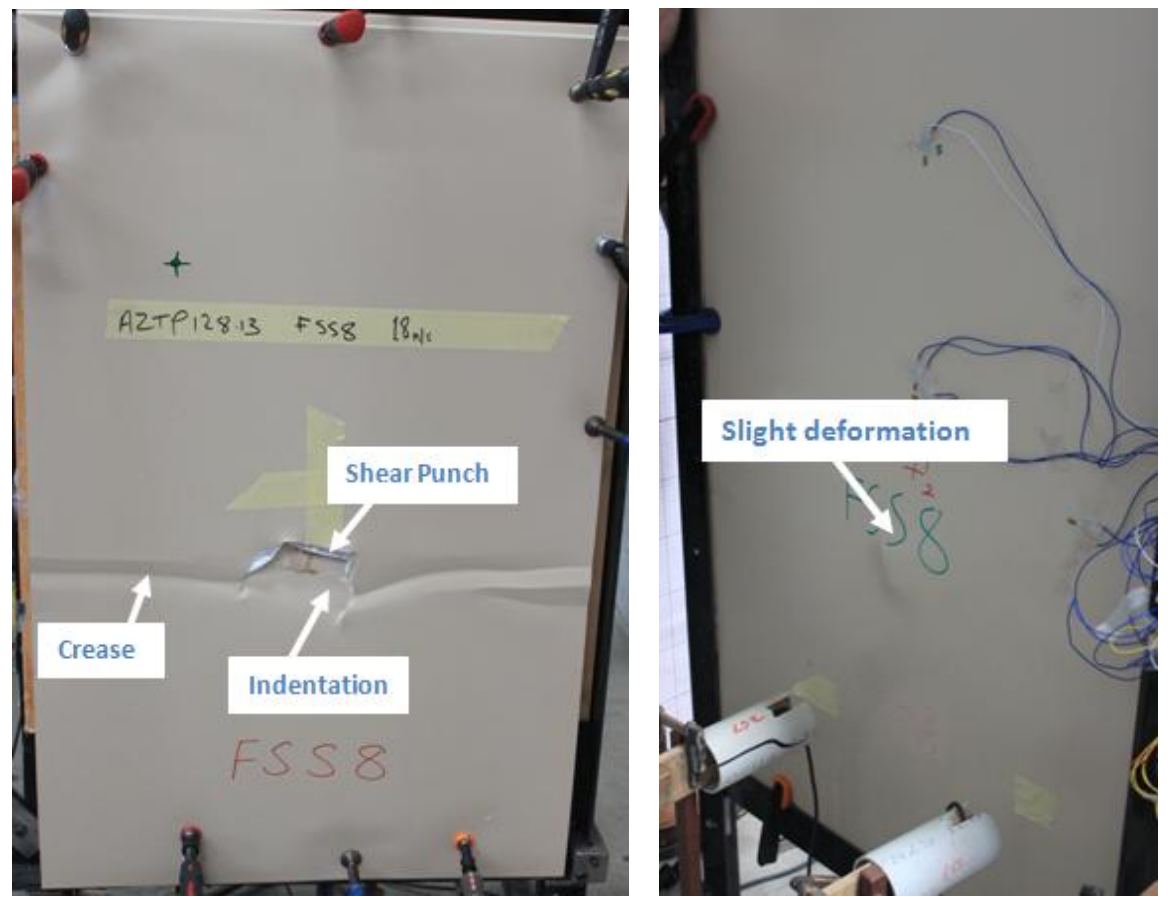

Figure 8 Photographs of specimen FSS8 (L) front view; (R) back view 


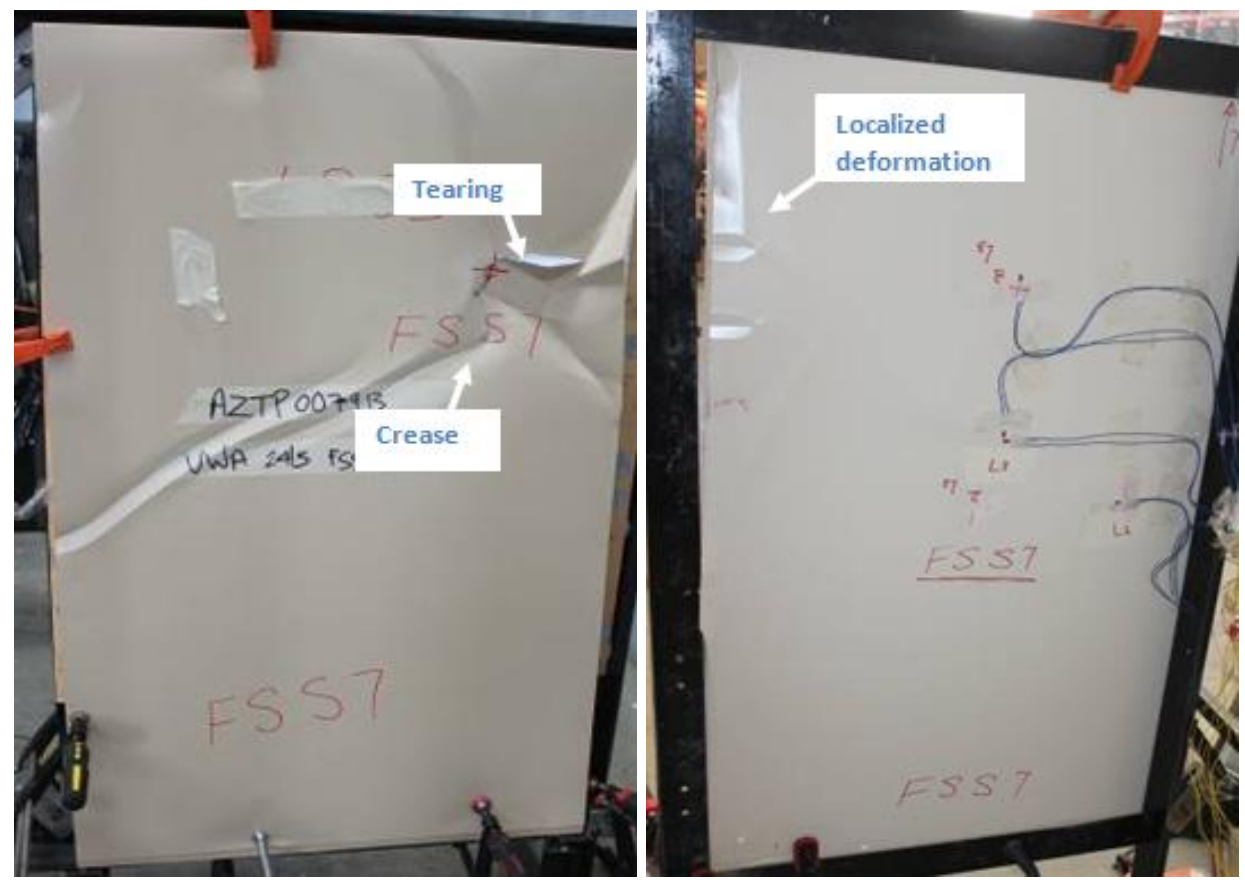

Figure 9 Photographs of specimen FSS7 (L) front view; (R) back view 


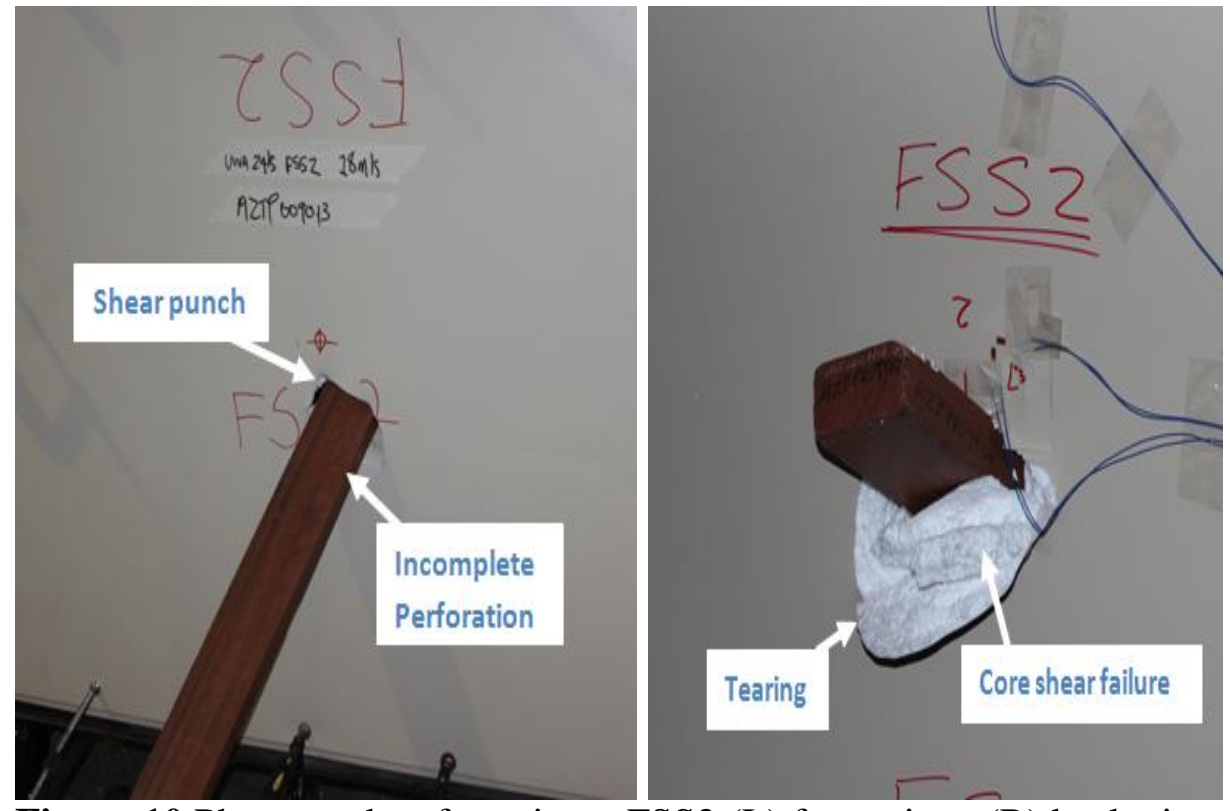

Figure 10 Photographs of specimen FSS2 (L) front view; (R) back view 


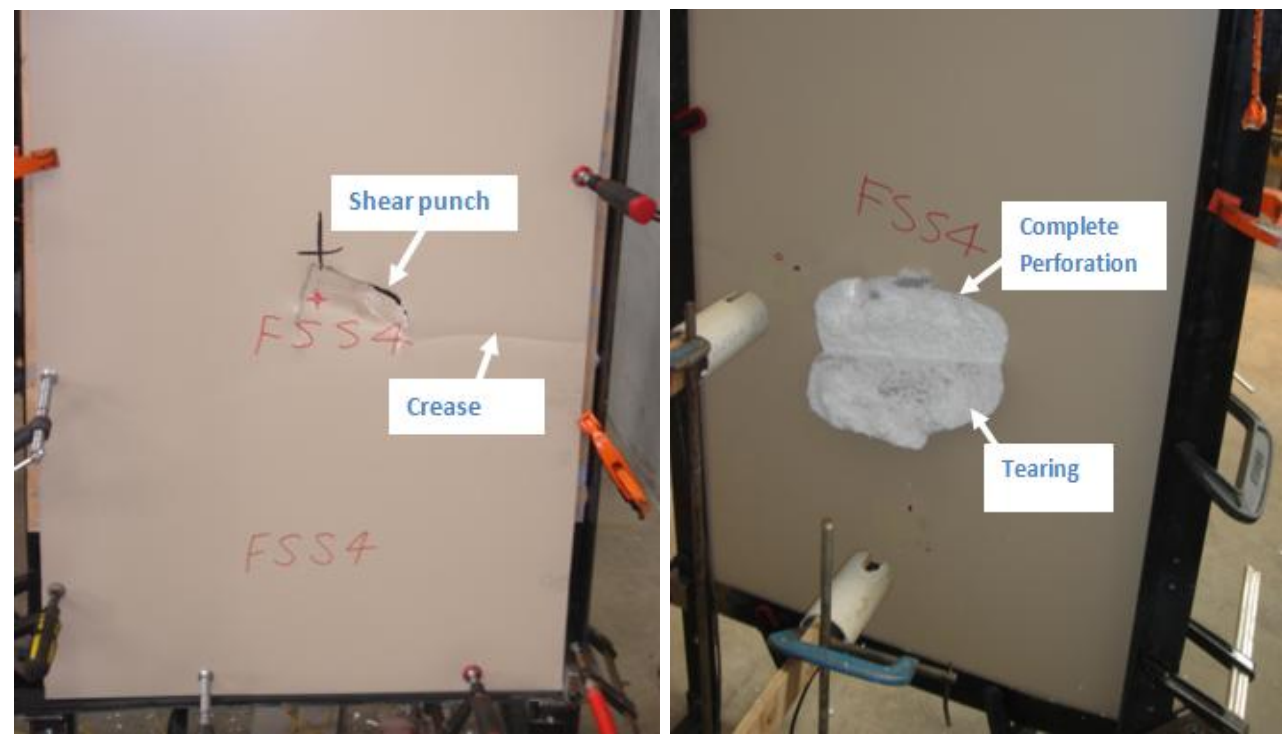

Figure 11 Photographs of specimen FSS4 (L) front view; (R) back view 


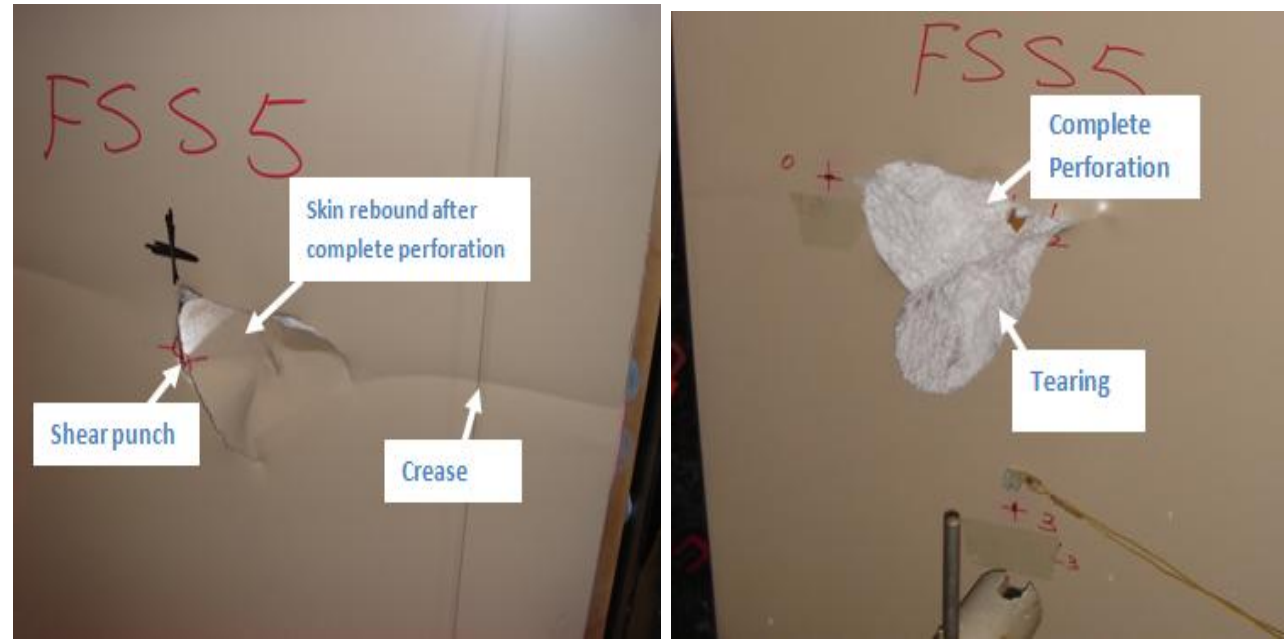

Figure 12 Photographs of specimen FSS5 (L) front view; (R) back view 


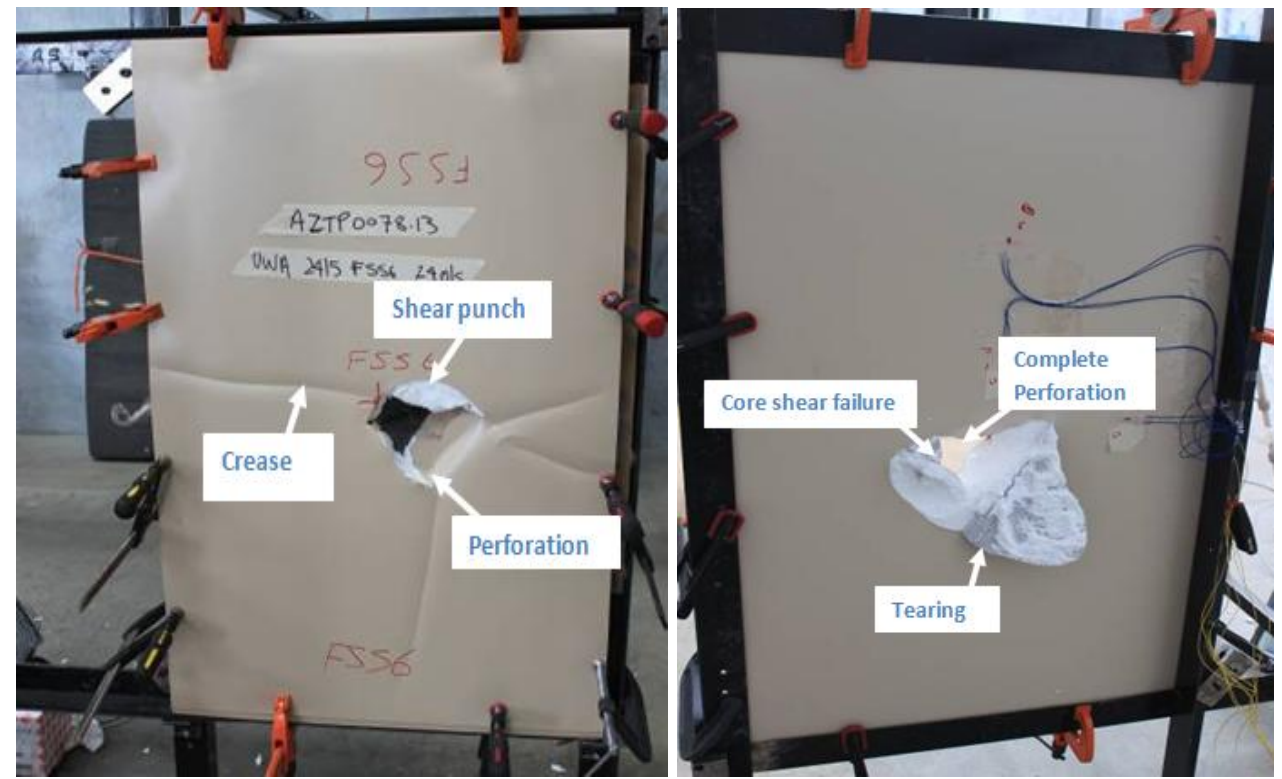

Figure 13 Photographs of specimen FSS6 (L) front view; (R) back view 

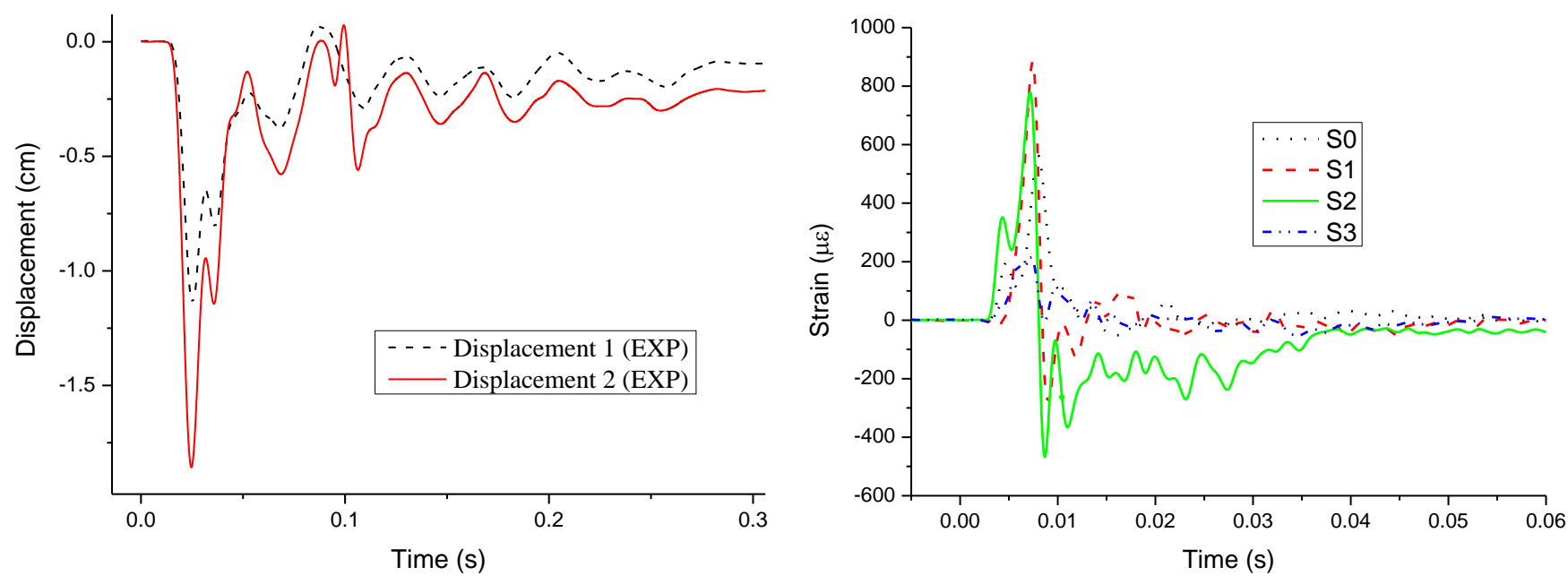

Figure 14 Specimen FSS6 (L) Displacement-time histories; (R) Strain-time histories 


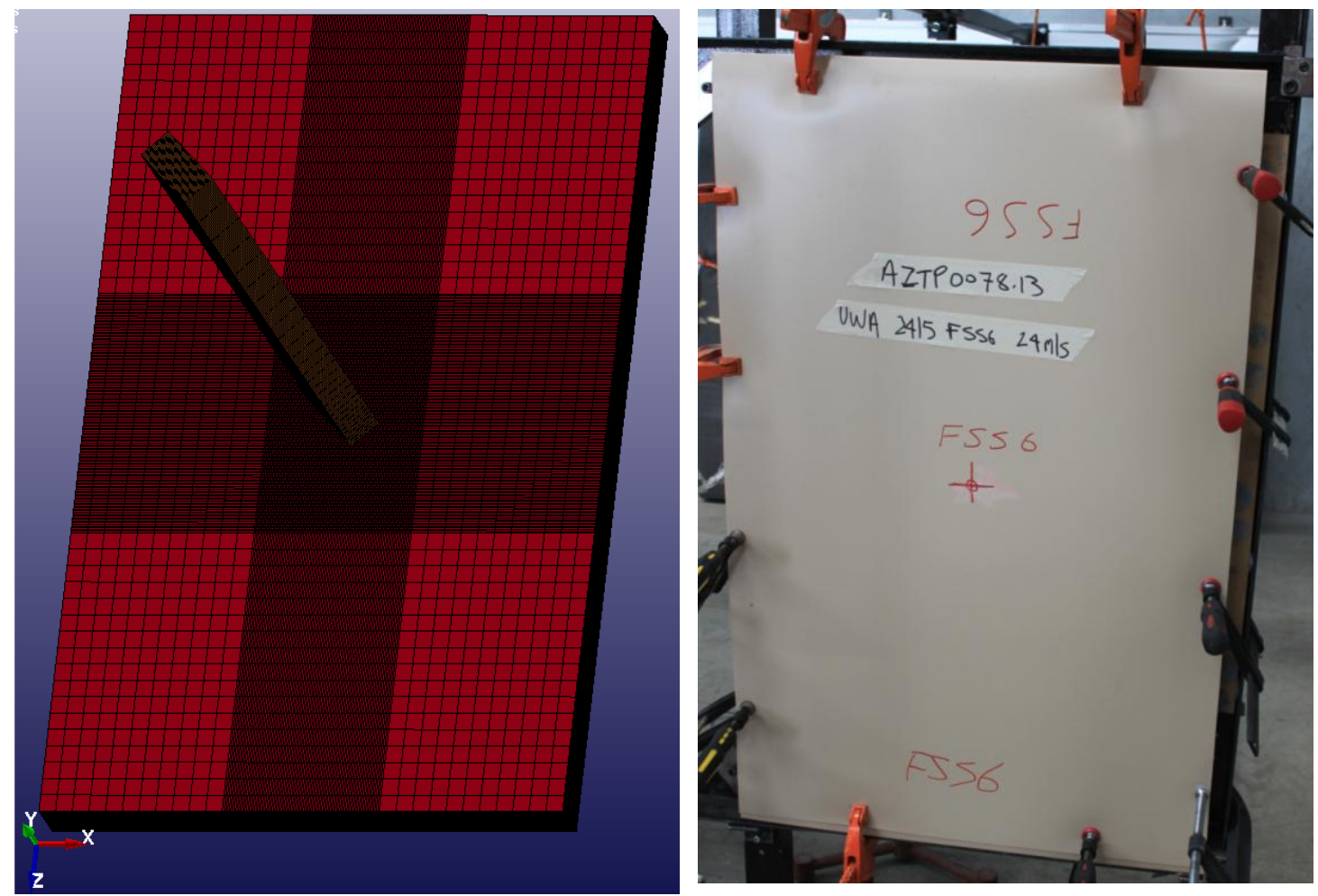

Figure 15 (L) Numerical model; (R) Experimental setup 


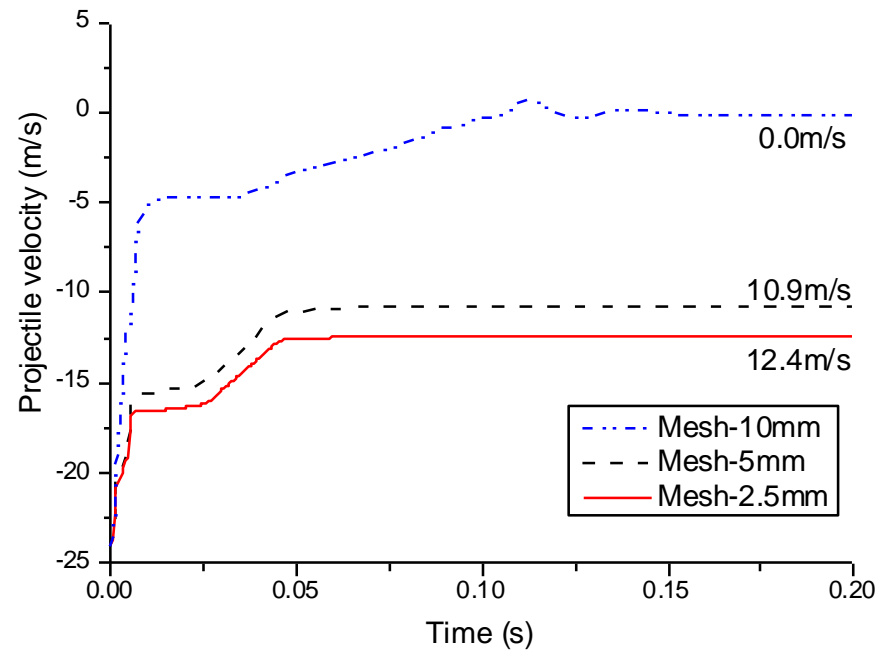

Figure 16 Residual projectile velocity time histories obtained with different mesh sizes 


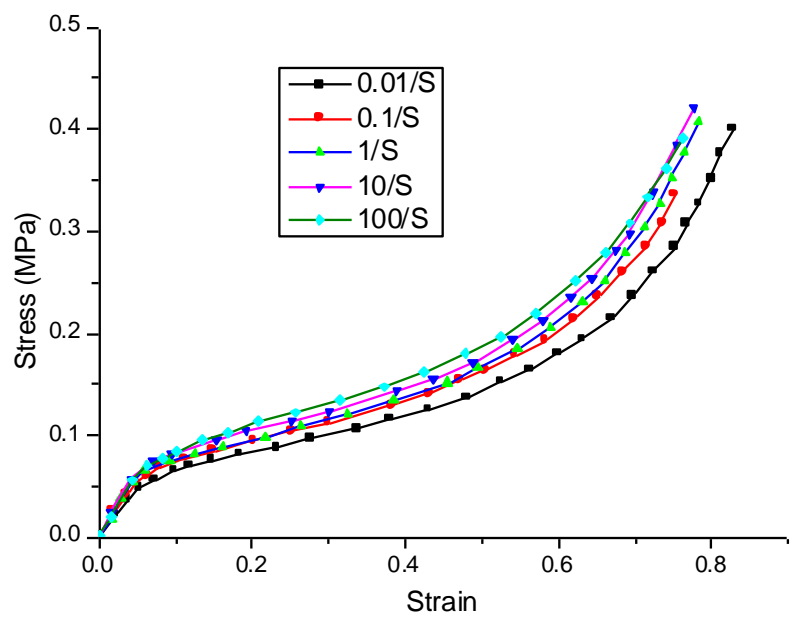

Figure 17 Stress-strain curves of EPS foam (density $16 \mathrm{~kg} / \mathrm{m}^{3}$ ) [40] 


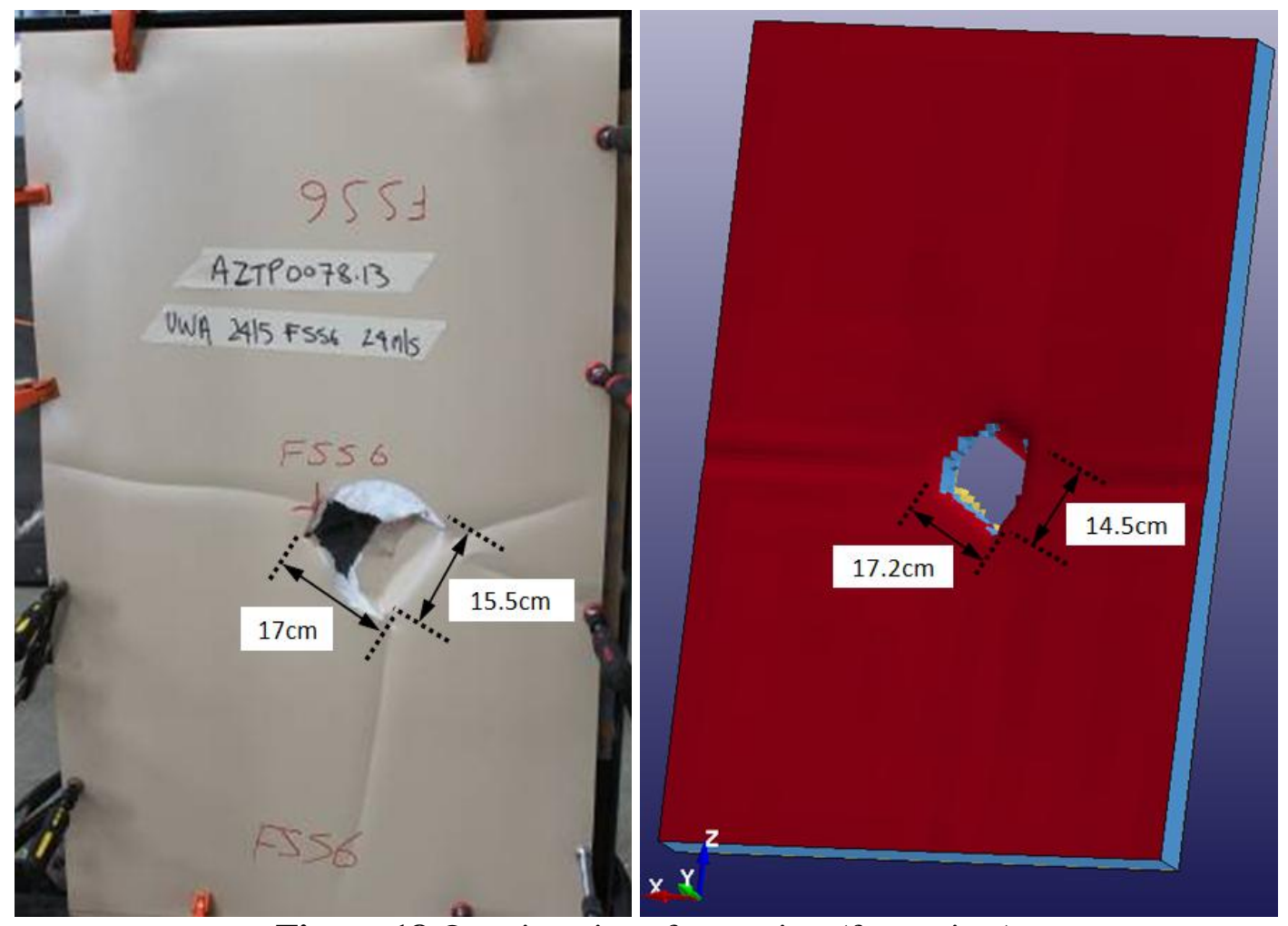

Figure 18 Opening size after testing (front view) 

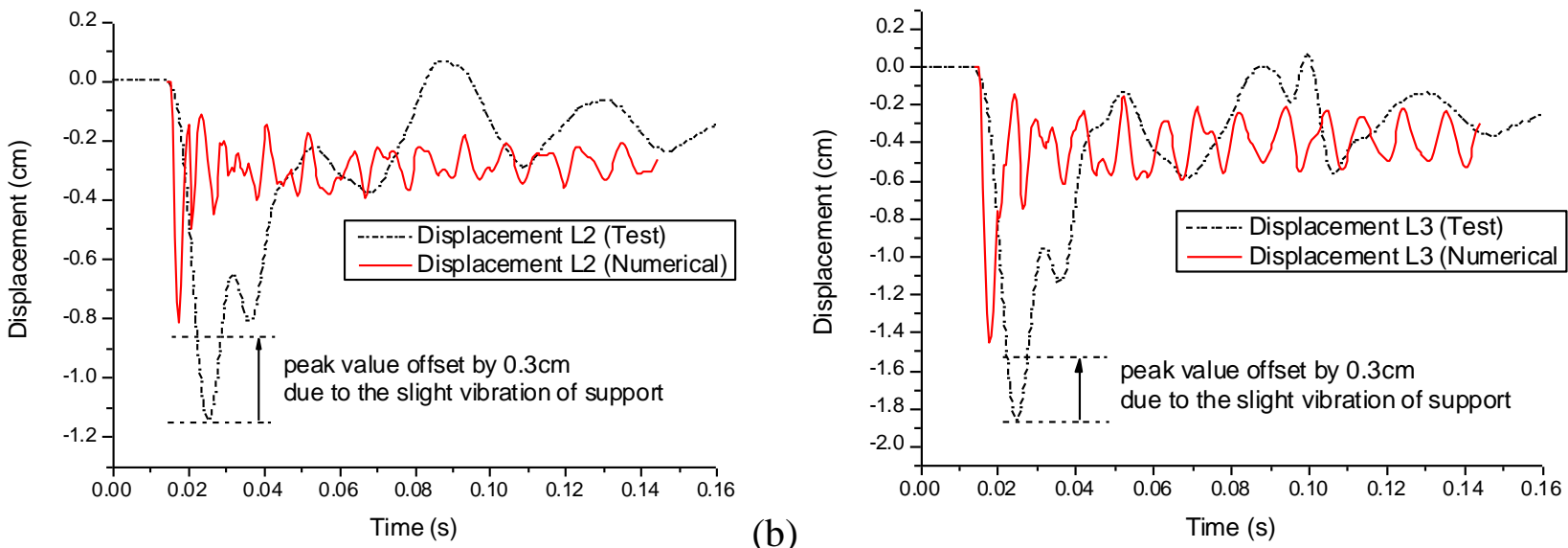

(a)

(b)

Figure 19 Comparison of displacement-time histories from numerical simulation and experimental test of specimen FSS6 (a) Location L2; (b) Location L3 
(a)
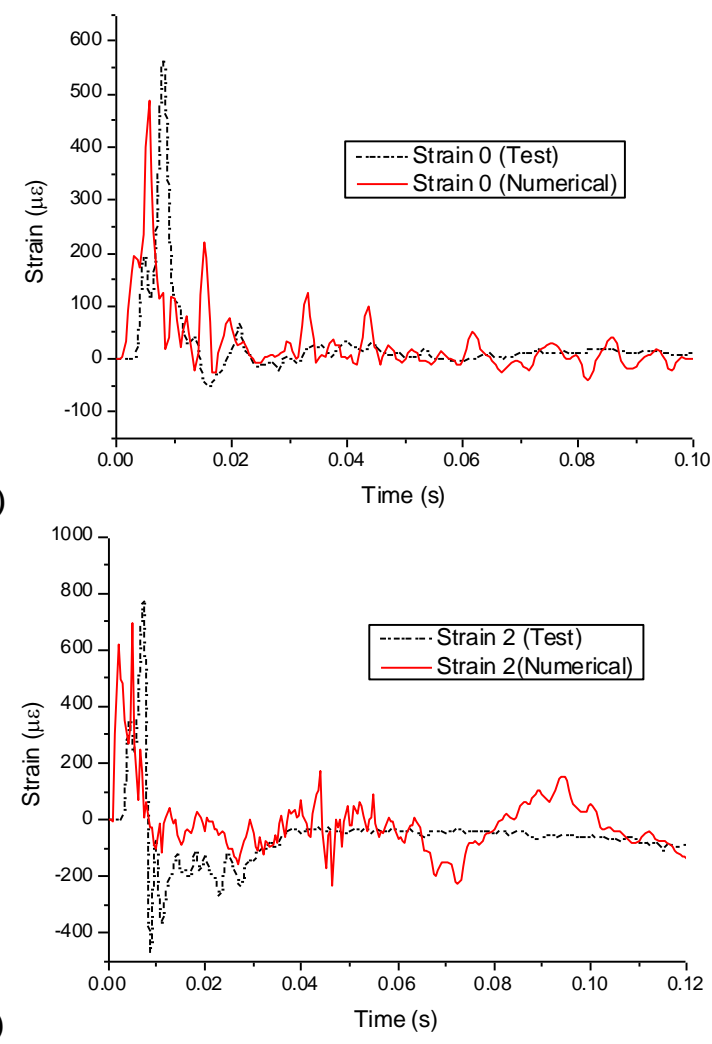

(b)
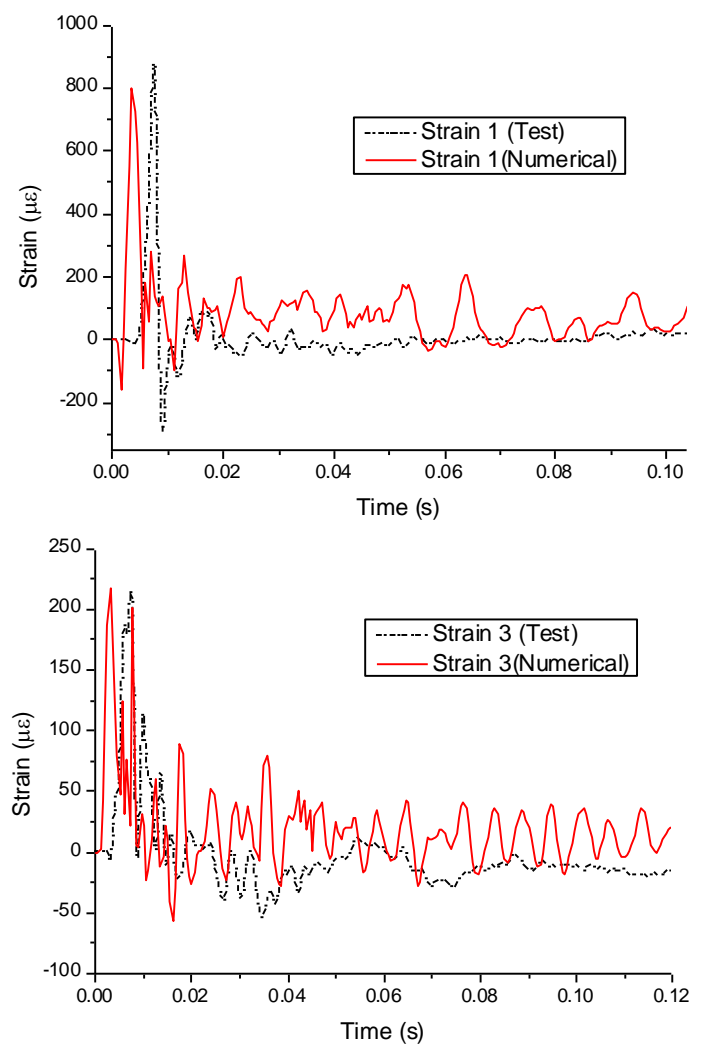

Figure 20 Comparison of strain-time histories from numerical simulation and experimental test of specimen FSS6 (a) Strain 0; (b) Strain 2; (c) Strain 3; (d) Strain 4 


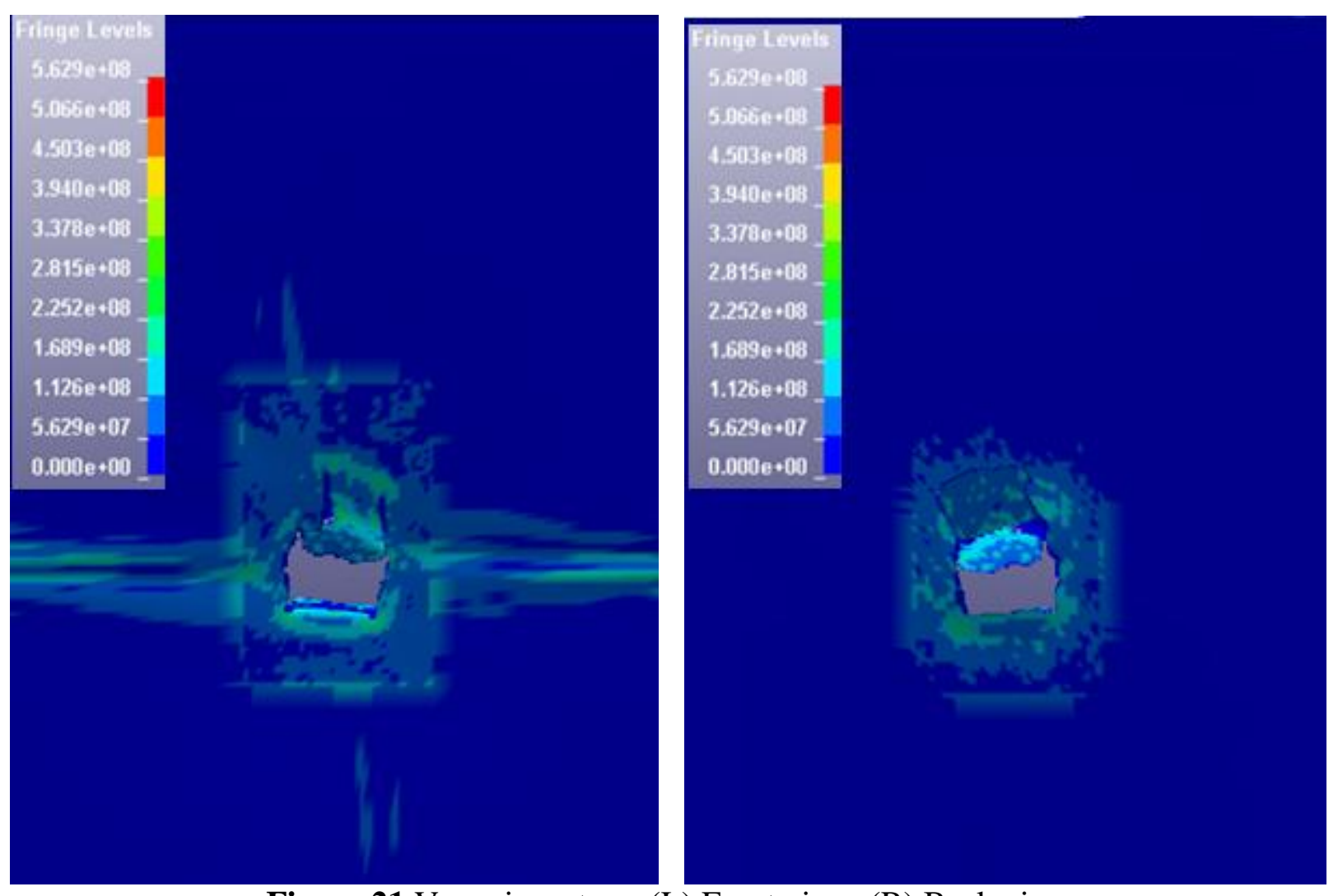

Figure 21 Von mises stress (L) Front view; (R) Back view 


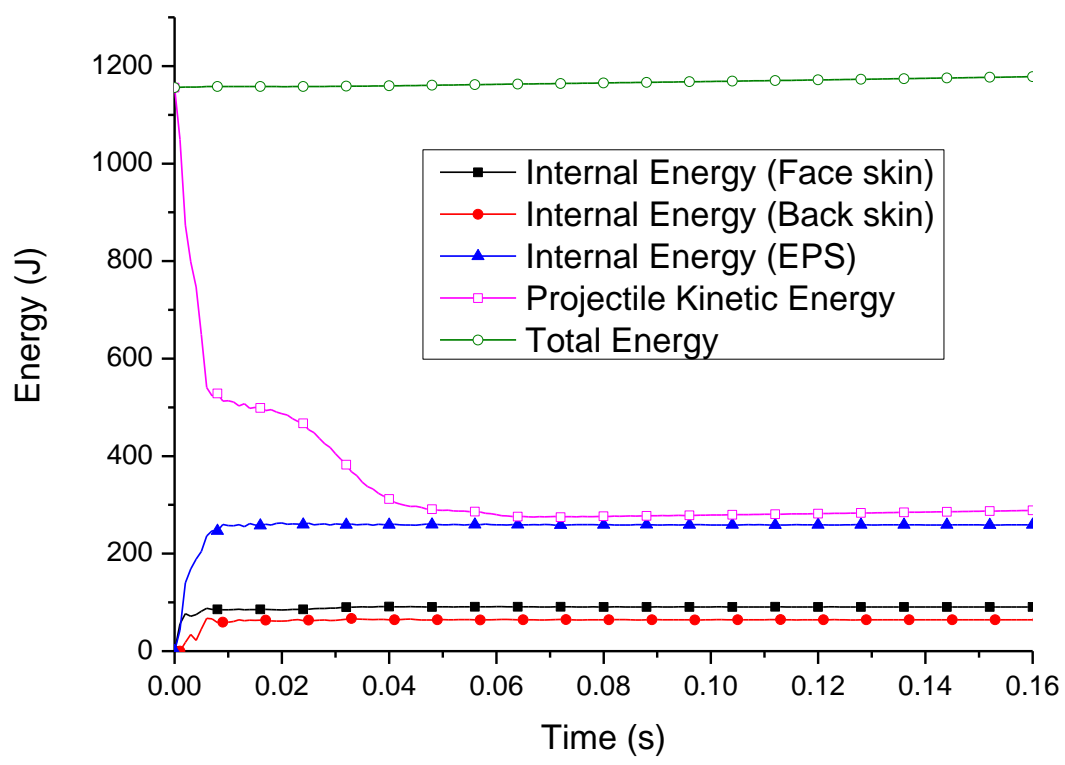

Figure 22 Time history of energy absorption 


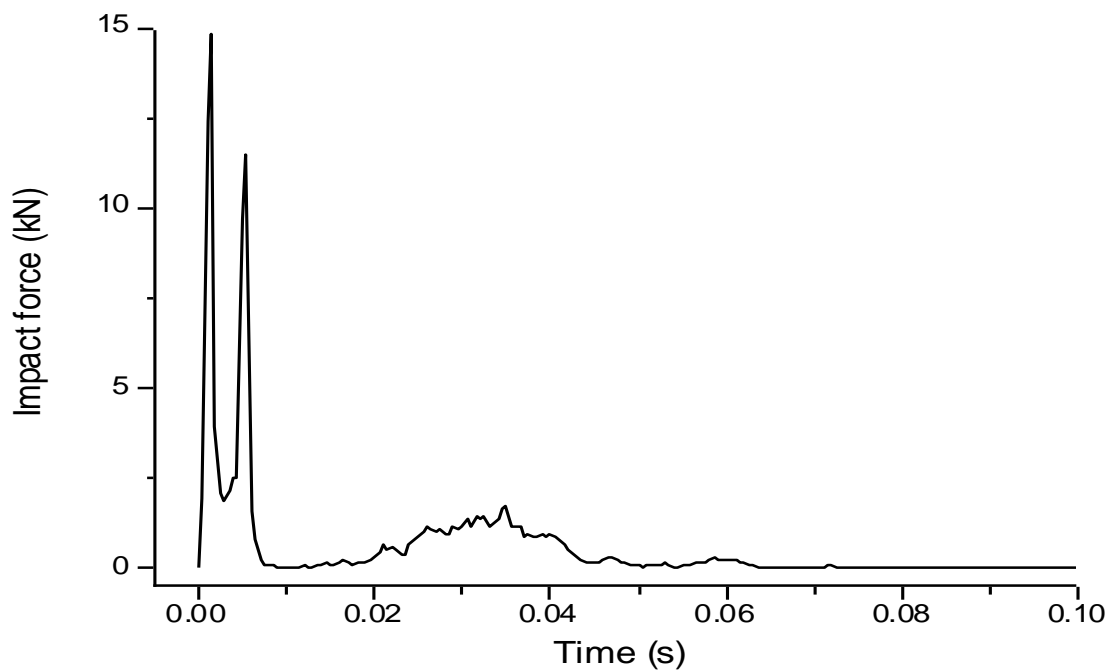

Figure 23 Impact force time-histories 


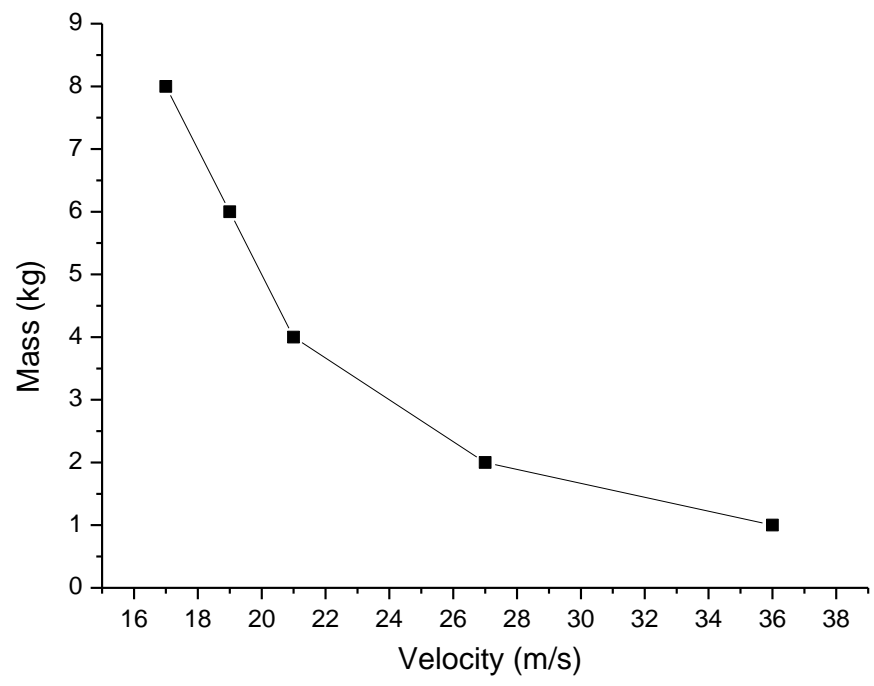

Figure 24 Panel penetration vulnerability curve 